\title{
1 Spacing and strength of active continental strike-slip faults
}

3 Andrew V.Zuza ${ }^{1}$ (corresponding author: avz5818@gmail.com; azuza@ucla.edu), An Yin ${ }^{1,2}$,

$4 \quad$ Jessica $\operatorname{Lin}^{1}$, and Ming $\operatorname{Sun}^{3}$

5

$6{ }^{1}$ Department of Earth, Planetary, and Space Sciences, University of California, Los Angeles, CA

7 90095-1567, USA

$8 \quad{ }^{2}$ Structural Geology Group, China University of Geosciences (Beijing), Beijing 100083, China

$9 \quad{ }^{3}$ School of Earth Sciences and Resources, China University of Geosciences (Beijing), Beijing

10 100083, China

11

12 Submitted to: EPSL

13 Submission Date: February $2^{\text {nd }}, 2016$

14 Revision Submission Date: April 13 ${ }^{\text {th }}, \mathbf{2 0 1 6}$

15 Second Revision Submission Date: July $\mathbf{1 0}^{\text {th }}, \mathbf{2 0 1 6}$

16 Third Minor Revision Submission Date: September $13^{\text {th }}, 2016$

17 


\section{ABSTRACT:}

Parallel and evenly-spaced active strike-slip faults occur widely in nature across diverse tectonic settings. Despite their common existence, the fundamental question of what controls

21 fault spacing remains unanswered. Here we present a mechanical model for the generation of 22 parallel strike-slip faults that relates fault spacing to the following parameters: (1) brittle-crust 23 thickness, (2) fault strength, (3) crustal strength, and (4) the crustal stress state. Scaled analogue 24 experiments using dry sand, dry crushed walnut shells, and viscous putty were employed to test 25 the key assumptions of our quantitative model. The physical models demonstrate that fault 26 spacing $(S)$ is linearly proportional to brittle-layer thickness $(H)$, both in experiments with only

27 brittle materials and with two-layer trials involving dry sand overlying viscous putty. The $S / h$ 28 slope in the two-layer sand-putty experiments may be controlled by the (1) rheological/geometric 29 properties of the viscous layer, (2) effects of distributed basal loading caused by the viscous 30 shear of the putty layer, and/or (3) frictional interaction at the sand-putty interface (i.e., coupling 31 between the viscous and brittle layers). We tentatively suggest that this third effect exerts the 32 strongest control on fault spacing in the analogue experiments. By applying our quantitative model to crustal-scale strike-slip faults using fault spacing and the seismogenic-zone thickness

34 obtained from high-resolution earthquake-location data, we estimate absolute fault friction of 35 active strike-slip faults in Asia and along the San Andreas fault system in California. We show that the average friction coefficient of strike-slip faults in the India-Asia collisional orogen is

37 lower than that of faults in the San Andreas fault system. Weaker faults explain why deformation 38 penetrates $>3500 \mathrm{~km}$ into Asia from the Himalaya and why the interior of Asia is prone to large 39 $(M>7.0)$ devastating earthquakes along major strike-slip faults. Our new approach of estimating 
40 absolute fault strength may be useful in future studies of continental deformation and earthquake 41 mechanics.

43 Keywords: Strike-slip fault spacing; San Andreas fault system; Central Asia; absolute fault 44 friction; seismogenic zone thickness; analogue modeling

\section{Introduction}

Parallel strike-slip faults occur widely in nature, from a few meters to $>100 \mathrm{~s} \mathrm{~km}$ in length and spacing (e.g., Segall and Pollard, 1983; Davy and Cobbold, 1988; Swanson, 1988; Martel and Pollard, 1989; Dickinson, 1996; Yin, 2010). Regularly spaced strike-slip faults are observed along plate transform boundaries (e.g., the San Andreas fault system; Fig. 1a) (e.g., Nur et al., 1986; Dickinson, 1996), across collisional orogens (e.g., the Himalayan-Tibetan orogen; Fig. 1b)

52 (Molnar and Tapponnier, 1975; Taylor and Yin, 2009; Yin, 2010; Zuza and Yin, 2016), in analogue experiments (e.g., Tchalenko, 1970; Freund, 1974; Naylor et al., 1986; Yin and Taylor,

54 2011), and on icy satellites in the outer solar system (e.g., Yin et al., 2016). Irregularly spaced

55 parallel strike-slip systems have also been documented, including the seismically active right-slip

56 fault systems across northern China where fault spacing varies from $\sim 100 \mathrm{~km}$ to $\sim 500 \mathrm{~km}$ (e.g.,

57 Yin et al., 2015). The characteristic spacing of strike-slip faults, or lack thereof, inevitably

58 reflects how the faults interact with one another and with the fault-bounded crust. Thus, this

59 readily observed geometric parameter may be used to estimate fault strength and stress state

60 across diverse tectonic settings on Earth and other solar system bodies. Despite being such a

61 common feature in zones of lithospheric deformation, the mechanics of evenly-spaced active

62 continental strike-slip faults has never been satisfactorily explained nor quantified. 
In this contribution, we develop a stress-shadow model (e.g., Lachenbruch, 1961; Yin et

64 al., 2016) that relates strike-slip-fault spacing to the brittle-crust thickness of the fault-hosting

65 lithosphere, fault and crustal strength, and the remote regional stress. Our model assumptions are

66 tested and validated with scaled analogue experiments using dry sand, crushed walnut shells, and

67 viscous putty. These models use a basal shear device to generate Riedel shears in dry granular

68 materials. By experimenting with various thicknesses and viscosities of a putty layer beneath a

69 brittle layer, we also explore the effects of distributed versus localized basal shear on strike-slip

70 fault spacing.

71 Strike-slip fault spacing is linearly proportional to brittle-layer thickness in both our

72 analogue experiments and for crustal-scale faults. The application of our theoretical model using

73 seismogenic zone thickness and fault spacing observations allows us to estimate the effective

74 coefficient of fault friction $\left(\overline{\mu_{f}}\right)$ of strike-slip faults in actively deforming regions of on Earth.

75 This method leads to the finding that the faults in the India-Asia collisional orogen are weaker

$76\left(\overline{\mu_{f}}=\sim 0.10-0.20\right)$ than faults in the San Andreas transform system $\left(\overline{\mu_{f}}=\sim 0.15-0.21\right)$ in

77 California, which has implications for the mode and extent of continental tectonics away from

78 plate boundaries.

79

\section{Generating parallel strike-slip faults}

812.1 Existing models

82

The following models have been proposed to account for the generation of parallel strike-

83 slip faults: (1) reactivation of preexisting extensional joints in crystalline and/or other low-

84 porosity rock (e.g., Segall and Pollard, 1983; Martel and Pollard, 1989), (2) deformation bands

85 formation in high-porosity rocks (e.g., Aydin and Johnson, 1978; Fossen et al., 2007), and (3) 
viscoelastic models that predict strike-slip fault spacing based on the rheology contrasts of the upper and lower crust (Roy and Royden 2000a, 2000b).

The first two groups of models explain faulting in fixed tectonic settings (e.g., previously normal-faulted rocks or deformation-band generation in porous sandstone) at small spatial scales (i.e., $<\sim 1 \mathrm{~km}$ ) with specific pre-fault histories and rock properties. Therefore, they ultimately lack generality for crustal-scale deformation. For example, it is unlikely that strike-slip faulting at a range of scales from $<1 \mathrm{~mm}$ to $>1000 \mathrm{~s} \mathrm{~km}$ across diverse lithologies (e.g., Fig. 1) is universally derived from the reactivation of preexisting regularly-spaced structures. We note that strike-slip faulting in northern Tibet and certain regions of California may be respectively exploiting suture zones and older normal faults (e.g., Taylor and Yin, 2009; Dokka, 1989), but the majority of the faults in both settings actually crosscut preexisting fabrics (Fig. 1) (Dickinson, 1996; Yin and Taylor, 2011). The deformation band mechanism (Aydin and Johnson, 1978) leads to strain localization and strain hardening, which in turn can produce through-going faults. This process predicts sequential initiation and deactivation of individual faults, but does not explain coeval motion of parallel strike-slip faults that occur independent of the fault-hosting lithology.

The viscoelastic models of Roy and Royden (2000a; 2000b) examine the effects of rheological stratification on strike-slip faulting. These studies show that fault spacing varies as a function of the strength of the upper crust and viscosity contrast between the upper and lower crust. Two limitations hinder the applicability of these models to actual continent-scale strikeslip faults: (1) the fault-parallel shear stress has an infinite value (i.e., a singularity) at the lower tip of the faults in their dislocation model and (2) when one fault is active, the other faults are assumed to be completed locked and inactive (i.e., total welding of the other faults), which 
109 implies that the faults are created sequentially, but not active simultaneously, as commonly 110 observed on Earth (Fig. 1).

\subsection{Stress-shadow model for extensional joints}

Our analysis of strike-slip fault spacing employs the stress-shadow model, which was

114 originally developed to quantify the spacing of extensional joints (Lachenbruch, 1961). Rock

115 under regional remote tensile stress, $\sigma_{n}={\sigma_{n}}^{r}$, fractures if ${\sigma_{n}}^{r}$ exceeds the tensile strength of the

116 rock $T$ (Fig. 2). The presence of a new fracture imposes a low stress boundary condition; for

117 extensional joints, the normal stress on the fracture surface $\sigma_{n}{ }^{c}$ is assumed to drop to zero

118 (Pollard and Segall, 1987). This in turns casts a stress shadow within which tensile stress is

119 below the tensile strength of the rock. This condition prohibits fractures from forming adjacent to

120 the initial joint. Stress increases away from the fracture $\sigma_{n}(x=0)=\sigma_{n}{ }^{c}=0$ to the regional

121 tensile stress $\sigma_{n}(x=\infty)={\sigma_{n}}^{r}$ (Fig. 2). The distance at which $\sigma_{n}$ surpasses $T$ defines the stress-

122 shadow length, $S$, such that $\sigma_{n}(x=S)=T$ (Fig. 2). New fractures can only be created

123 immediately outside of the stress shadows, resulting in a characteristic joint spacing. The stress

124 rise in the above scenario (Fig. 2) can be quantified by an analytical solution of the stress-

125 distribution for mode-I opening cracks from linear elastic fracture mechanics (LEFM)

126 (Lachenbruch, 1961; Pollard and Segall, 1987; Gross, 1993).

\subsection{Stress-shadow model for strike-slip faulting}

The stress-shadow model for strike-slip faulting used in this study is based in part on a 130 derivation presented in Yin et al. (2016), which examined strike-slip fault spacing on Enceladus

131 (an icy satellite of Saturn) to infer its ice-shell thickness and frictional strength. In both Yin et al. 
132 (2016) and this study, we (1) treat a strike-slip fault as a vertical shear fracture cutting through a

133 brittle layer with its motion driven by a remote fault-parallel shear stress, (2) seek the fault-

134 motion-parallel shear stress distribution, (3) regard the deforming lithosphere as a plastic

135 material governed by the Coulomb fracture criterion, and (4) assume that crustal strength resides

136 dominantly in the brittle crust, consistent with the stress-guide concept (Lister and Davis, 1989)

137 and the current understanding of continental lithosphere rheology (e.g., Jackson et al., 2008).

$$
\begin{array}{r}
\sigma_{x z}(x=0)=\overline{\sigma^{f}} \\
\sigma_{x z}(x=\infty)=\sigma_{s}^{r}=\sigma^{b c}
\end{array}
$$

141 where $x$ is the distance from the fault (Fig. 3), $\overline{\sigma^{f}}$ is the vertically-averaged shear stress on the 142 fault plane, and $\sigma_{s}^{r}$ is the regional shear stress, which we denote as $\sigma^{b c}$ (" $b c$ " stands for boundary 143 condition). The boundary condition in equation (1a) is an important departure from the stress-

144 shadow model for extensional jointing, as the magnitude of the shear stress on a strike-slip fault

145 is not zero, but rather equals the vertically averaged shear stress of the fault plane, $\overline{\sigma^{f}}$ (Fig. 3)

146 (cf. Roy and Royden, 2000a, 2000b). The following solution for the shear stress distribution

147 satisfies the boundary conditions in equations (1a) and (1b):

$$
\sigma_{x Z}(x)=\sigma^{b c}+\left(\sigma^{b c}-\overline{\sigma^{f}}\right)\left[\frac{|x|^{n / m}}{\left(|x|^{n}+h^{n}\right)^{1 / m}}-1\right]
$$

149 where $x$ is the distance from the fault, $h$ is the depth of the fault equal to the brittle-crust

150 thickness in the $y$ direction, $n>0$, and $m>0$ (Fig. 3). The above solution is not unique when it is 151 constrained by the boundary conditions alone because it lacks information on the rheology of the 152 deforming fault-hosting material. For example, the following solution also satisfies the boundary 153 conditions shown in equations (1a) and (1b): 


$$
\sigma_{x z}(x)=\sigma^{b c}+\left(\sigma^{b c}-\overline{\sigma^{f}}\right)\left[\frac{\tan ^{-1}(x)}{\left(\frac{\pi}{2}\right)}-1\right]
$$

where $\tan ^{-1}(x=0)=0$ and $\tan ^{-1}(x=\infty)=\frac{\pi}{2}$, thus allowing $\sigma_{x z}(x=0)=\overline{\sigma^{f}}$ and $\sigma_{x z}(x=$ $\infty)=\sigma^{b c}$. However, as we show below, the solution in equation (2) permits a linear relationship between $S$ and $h$, which is observed in our analogue experiments and continental strike-slip fault data (see below in sections 3 and 4), whereas equation (3) does not have this mathematical property.

Using equation (2), the length of the stress shadow $S$ can be obtained by:

$$
\sigma_{x z}(x=S)=\bar{Y}=\sigma^{b c}+\left(\sigma^{b c}-\overline{\sigma^{f}}\right)\left[\frac{S^{n / m}}{\left(S^{n}+h^{n}\right)^{1 / m}}-1\right]
$$

where $\bar{Y}$ is the vertically averaged shear fracture strength within the domain of strike-slip faulting (Fig. 3). Note that $\bar{Y}$ is analogous to the tensile strength $T$ in the extensional joint example discussed above.

When $n=m=2$, equations (2) and (4) have a superficial similarity to the LEFM solution for the shear stress distribution of a mode-III crack, embedded in an elastic half space, at the Earth's surface (Pollard and Segall, 1987). However, because major continental strike-slip faults cut through the entire brittle crust (e.g., Fig. 1), a half-crack in an elastic half space is not an ideal approximation (e.g., Yin et al., 2016). The LEFM solution assumes that fracture/fault generation is driven by stress at the free surface, which is viable for cracks in mud, ice, or volcanic rocks (e.g., Lachenbruch, 1961). However, this assumption is inconsistent with faultparallel stress increasing with depth for continental-scale faulting (see equation [8.44d] in Pollard and Segall, 1987; Gross, 1993), as this would imply that the minimum shear stress at the Earth's surface is primarily responsible for new nucleating faults. Another important difference 
175 is that our model does not create a stress singularity at the basal tip of the fault modeled as a half 176 crack in the classic treatment of Pollard and Segall (1987).

178 shown in equation (4) into stress equilibrium equations that are coupled with a rheological model 179 (e.g., elastic, plastic, viscoelastic, etc.) for the deforming material hosting the strike-slip faults. 180 Here we take an empirical approach by observing the relationship between $S$ and $h$ values in 181 nature and controlled laboratory experiments. As shown below, $S$ and $h$ are best described by a 182 linear relationship (i.e., $S / h$ ratios are constant), and this simple observation requires that $m=n=$ 1831 in equation (4).

\section{Analogue modeling}

Starting with the observation that extensional-joint spacing is linearly proportional to the

187 thickness of the joint-hosting layer (e.g., Bai and Pollard, 2000), we set out to investigate 188 whether a similar linear relationship holds for strike-slip fault spacing and brittle-layer thickness.

189 Scaled analogue experiments were conducted using dry granular materials, which can simulate 190 brittle-crust deformation (e.g., Davy and Cobbold, 1988). Our experiments use a 12-cm-wide 191 basal-sliding-plate device to generate two parallel shear zones in which Riedel shears form (see

192 Yin and Taylor, 2011) (Fig. 4). The model boundary-wall dimensions $(65 \mathrm{~cm} \times 70 \mathrm{~cm})$ are an 193 order of magnitude larger than the width of the shear zones created in the experiments, which are 194 typically $\leq 6 \mathrm{~cm}$ (Fig. 4a).

195 One set of experiments use a single layer of dry sand or crushed walnut shells to 196 determine the relationship between brittle-layer thickness and fault spacing. The second set of 
197 experiments include a ductile putty layer underneath the frictional materials to examine the role

198 of a viscous layer in controlling the relationship between fault spacing and brittle-layer thickness.

\subsection{Experimental materials}

We use two different granular materials for the brittle layer-commercially available dry sand and crushed walnut shells (e.g., Hubbert, 1937, 1951; Davy and Cobbold, 1988; Cruz et al., 2008) - for two distinct reasons. First, they have different frictional properties, which allows for more rigorous testing of the analytical model predictions against our observed physical models.

205 Second, the materials have different densities (i.e., $1670 \mathrm{vs.} 790 \mathrm{~kg} / \mathrm{m}^{3}$ for sand and crushed walnut shells, respectively), which results in slightly different scaling relationships between the 207 model and nature (see section 3.2). type apparatus (Hubbert, 1951), which involves constructing a shear stress versus normal stress failure envelope for each of the experimental materials (e.g., Cruz et al., 2008). The shear stress

211 that generates Riedel shear fractures is a function of the basal friction $\left(\mu_{b}\right)$ beneath the 212 sand/crushed walnut shells (see section 4.2). Therefore we quantify $\mu_{b}$ between the (1) granular 213 materials and underlying basal-sliding plate covered by P100 sandpaper ( 162 $\mu \mathrm{m}$ grain size) 214 and (2) dry sand and putty layer. This second interface consists of sand embedded in the putty, 215 which creates a sticky sandpaper-like surface. The grain size distributions and measured 216 frictional properties of our granular materials are reported in Table $\mathbf{1}$ and Figure A1. All of 217 these procedures were repeated at least five times to generate statistical uncertainties. 
220 putty. The strain rate of simple-shear flow of the putty with an overlying mass on an inclined

221 surface can be used to calculate the viscosity following the relationship $\tau=\eta \dot{\gamma}$, where $\tau$ is shear

222 stress, $\eta$ is viscosity, and $\dot{\gamma}$ is shear strain rate. Note that because of this relationship, our

223 experiments using different viscosity putties also incorporate the effects of variable strain rates

224 (). The simple-shear experiments yield viscosities of $6.2 \times 10^{3} \mathrm{~Pa}$ s and $9.5 \times 10^{3} \mathrm{~Pa}$ s for the two

225 types of putties.

226

227

\subsection{Scaling considerations}

228

Relating the analogue experiments to crustal-scale strike-slip faults requires dynamic and

229 geometric scaling governed by the following relationships (Hubbert, 1937):

$$
\frac{C^{\text {model }}}{C^{\text {nature }}}=\frac{\sigma_{V}^{\text {model }}}{\sigma_{V}^{\text {nature }}}=\frac{\rho^{\text {model }} \times l^{\text {model }} \times g^{\text {model }}}{\rho^{\text {nature }} \times l^{\text {nature }} \times g^{\text {nature }}}
$$

where superscripts model and nature denote the model and crustal parameters and $l, \sigma_{V}, \rho$, and $g$

232 are vertical thickness, vertical stress, density, and the gravitational acceleration at the Earth's

233 surface, respectively. As the densities of the model and crustal materials are of the same order of

234 magnitude (e.g., $1670 \mathrm{~kg} / \mathrm{m}^{3}$ for sand versus $2750-3100 \mathrm{~kg} / \mathrm{m}^{3}$ for rock), appropriate scaling

235 depends primarily on the cohesive-strength ratio. The cohesive shear strength of rock varies

236 greatly depending on rock type, ranging from $20 \mathrm{MPa}$ to $110 \mathrm{MPa}$ (Jaeger et al., 2009). Our

237 experimental materials have a cohesive strength $\left(C^{\text {model }}\right)$ of 40-60 Pa (Table 1), and if we take

238 rock cohesive strength $\left(C^{\text {nature }}\right)$ to be $50 \mathrm{MPa}$, we arrive at scaling relationships of sand and

239 crushed walnut shells of $l_{\text {sand }}^{\text {model }} \approx \sim 1.7 \times 10^{-6} l^{\text {nature }}$ and $l_{\text {walnut }}^{\text {model }} \approx \sim 3.5 \times 10^{-6} l^{\text {nature }}$

240 respectively, where the superscripts sand and walnut refer to each experimental material.

241 Accordingly, $1 \mathrm{~cm}$ sand thickness in our experiments represents $\sim 6 \mathrm{~km}$ crustal thickness. Our

242 experiments, which use layer thicknesses of 1-6 cm for sand and 3-7 $\mathrm{cm}$ for crushed walnut 
243 shells, can simulate deformation of the crust with overlapping thicknesses of $\sim 6-36 \mathrm{~km}$ and $\sim 3-$

$24421 \mathrm{~km}$ for each material, respectively.

245

\subsection{Experimental procedure and results}

The first set of experiments was run with dry granular materials (i.e., sand and crushed

248 walnut shells) with thicknesses ranging from $1 \mathrm{~cm}$ to $7 \mathrm{~cm}$. Trials run with thicknesses of $<1 \mathrm{~cm}$ or $>7 \mathrm{~cm}$ failed to produce observable shear fractures. Sandpaper was used for friction between

250 the materials and the apparatus. In the second series of experiments, the viscous-putty layer was

251 overlain by a sand layer. Both the viscosity and thickness of the putty were varied to observe

252 their effects on fault spacing. Experiments were run with 7-mm- (Fig. 4c) and 13-mm-thick putty

253 layers underneath a dry-sand layer with varying thicknesses (1 to $5 \mathrm{~cm}$ ). Five trials were repeated

254 for each experiment of varying thicknesses of granular materials. The perpendicular distance

255 between the Riedel shears was measured and the results from all five runs were averaged; the

256 calculated uncertainties are the standard deviation of our observations. Vertical-layer-thickness

257 uncertainty is $\sim 1 \mathrm{~mm}$.

258 Results from both sets of experiments can be explained by a simple linear relationships

259 between fault spacing $(S)$ and layer thickness $(h)$ (Figs. 4d and 4e). For the granular-material260 only trials, the following linear relationships are observed: $S / h=0.68 \pm 0.1$ for sand and $S / h=$

$2610.82 \pm 0.2$ for crushed walnut shells $($ Fig. $4 \mathbf{d})$.

262 The experiments with sand overlying a viscous-putty layer all show linear $S / h$

263 relationships ranging from $0.45 \pm 0.03$ to $0.58 \pm 0.07$ (Fig. 4e). A linear regression fits the

264 brittle-viscous experiments within uncertainties, but the range of fault-spacing data for the

265 thicker brittle layers (e.g., when $h>\sim 3-4 \mathrm{~cm}$ ) makes a definitive interpretation of this 
266 relationships ambiguous (Fig. 4e). For example, the large uncertainties also allow for a nonlinear

267 regressions of this data. However, because a linear relationship is permitted by our observations,

268 we assume the simplest scenario that $S$ and $h$ are linearly proportional. The larger variability of

269 fault spacing may arise when the fault spacing $S$ and experiment-model length $M$ ratio $(S / M)$

270 (Fig. 4a) becomes sufficiently high enough that contraction and extension along experimental

271 boundaries affect strike-slip fault generation and spacing.

272

273 4. A linear stress-shadow model for strike-slip faulting

$274 \quad 4.1$ Relationship between fault spacing and brittle-layer thickness

275

The linear $S$ - $h$ relationship observed in section 3 requires that $n=m=1$, which allows

276 simplification of equation (4) to the following relationship:

277

$$
S=\frac{\bar{Y}-\overline{\sigma^{f}}}{\sigma^{b c}-\bar{Y}} h
$$

278 Equation (6) demonstrates that fault spacing $S$ is a function of the (i) brittle-crust thickness $h$, (ii)

279 regional shear stress acting on the brittle crust $\sigma^{b c}$, (iii) shear fracture strength of the deforming

280 brittle crust $\bar{Y}$, and (iv) shear stress on the fault surface $\overline{\sigma^{f}}$. Fault shear stress and crustal shear

281 strength are pressure-, and therefore, depth-dependent, and their mean values can be obtained by

282 assuming that the normal stresses acting on the fault planes are lithostatic. From this assumption,

283 we determine:

$$
\overline{\sigma^{f}}=\frac{1}{h} \int_{0}^{h}\left(C_{1}+\overline{\mu_{f}} \rho g y\right) \mathrm{d} y=C_{1}+\frac{1}{2} \overline{\mu_{f}} \rho g h
$$

285 and

$$
\bar{Y}=\frac{1}{h} \int_{0}^{h}\left(C_{0}+\overline{\mu_{\varphi}} \rho g y\right) \mathrm{d} y=C_{0}+\frac{1}{2} \overline{\mu_{\varphi}} \rho g h
$$


287 where $\rho$ is the density of the deforming layer, $g$ is the gravitational acceleration, $C_{0}$ and $\overline{\mu_{\varphi}}$ are 288 the cohesive strength and the effective coefficient of internal friction for the crust next to the 289 fault, respectively, and $C_{l}$ and $\overline{\mu_{f}}$ are the cohesive strength of the fault and the effective 290 coefficient of fault friction, respectively. The effective coefficient of internal (i.e., crustal) and 291 fault friction are defined respectively as

$$
\begin{aligned}
& \overline{\mu_{\varphi}}=\left(1-\lambda_{\varphi}\right) \mu_{\varphi} \\
& \overline{\mu_{f}}=\left(1-\lambda_{f}\right) \mu_{f}
\end{aligned}
$$

294 where $\lambda_{\varphi}$ and $\mu_{\varphi}$ are the pore-fluid-pressure ratio and coefficient of internal friction of the fault295 bounded domains, respectively, and $\lambda_{f}$ and $\mu_{f}$ are the pore-fluid-pressure ratio and coefficient of 296 fault friction, respectively.

297 To quantify the regional shear stress acting on the boundaries of the strike-slip faulting 298 domains we first assume that shear strength is linearly proportional to the brittle-crust thickness 299 and that the strike-slip domains are bounded by stronger, thus thicker, but still deforming regions 300 (Fig. 3). If strike-slip faulting does not occur within these adjacent regions, the regional shear 301 stress must be below the shear fracture strength of these stronger and thicker domains. Therefore 302 we assume that the regional stress $\sigma^{b c}$ equals the vertically averaged shear strength of the 303 stronger but still deforming regions $\left(\overline{Y^{B R}}\right)$ bounding the strike-slip domain (Fig. 3). That is

$$
\sigma^{b c}=\overline{Y^{B R}}=\frac{1}{H} \int_{0}^{H}\left(C_{2}+\overline{\mu_{\varphi}^{B R}} \rho g y\right) \mathrm{d} y=C_{2}+\frac{1}{2} \overline{\mu_{\varphi}^{B R}} \alpha \rho g h
$$

305 where $C_{2}$ and $\overline{\mu_{\varphi}{ }^{B R}}$ are the cohesive strength and effective coefficient of internal friction of the 306 bounding regions, respectively, $H$ is the brittle-layer thickness of bounding regions, and $\alpha$ is a 307 proxy for regional-stress magnitude defined as $\alpha=H / h>1$ (Fig. 3). Using $\bar{Y}, \overline{\sigma^{f}}$, and $\sigma^{b c}$ from 
308

309

310

311

312

313

314

315

316

317

equations (7), (8), and (10), and assuming $\overline{\mu_{\varphi}^{B R}}=\overline{\mu_{\varphi}}$ and $C_{0}=C_{2}$, we derive the following $S$ - $h$ relationship:

$$
S=\frac{\left(C_{0}-C_{1}\right)+\frac{1}{2} \rho g h\left(\overline{\mu_{\varphi}}-\overline{\mu_{f}}\right)}{\frac{1}{2} \rho g h \overline{\mu_{\varphi}}(\alpha-1)} h
$$

Because $S$ is relatively insensitive to $\left(C_{0}-C_{1}\right)$ (Fig. 5a), we simplify equation (11) to:

$$
S=\frac{\left(\overline{\mu_{\varphi}}-\overline{\mu_{f}}\right)}{\overline{\mu_{\varphi}}(\alpha-1)} h
$$

and

$$
\overline{\mu_{f}}=\overline{\mu_{\varphi}}\left[1-\frac{s}{h}(\alpha-1)\right]
$$

Given that $\overline{\mu_{f}}>0$, the following relationship must also hold:

$$
\alpha \leq\left(\frac{h}{s}+1\right)
$$

Equation (14) indicates that for the same brittle-crust thickness, wider fault spacing requires lower values of $\alpha$. This means that a larger stress magnitude and/or stress gradient (i.e., a larger $\alpha$ value due to stronger bounding crust or weaker deforming crust) leads to more closely spaced strike-slip faulting because the stress rise is more rapid from $\sigma_{x z}(x=0)=\overline{\sigma^{f}}$ to $\sigma_{x z}(x=S)=$ $\bar{Y}$ (Figs. 3 and 5b). Fault strength $\overline{\mu_{f}}$ also affects $S$; larger values of $\overline{\mu_{f}}$ leads to smaller fault spacing $S$ (Fig. 5c).

\subsection{The stress-shadow model and our analogue experiments}

The fault-parallel shear stress generated by basal shearing in our analogue experiments differs from the depth-dependent fault-parallel shear stress assumed in our analytical solutions (e.g., equation [10]). That is, the fault-parallel shear stress in our experiments depends on the basal coefficient of friction but is independent of the vertical axis when solving the stress 
329

330

331

332

333

334

335

336

337

338

339

340

341

342

343

344

345

346

347

348

349

350

351

equilibrium equations (see derivation in Supplementary Material). Because of this difference, the detailed formation processes of strike-slip faults in nature and in our experiments are slightly different, although the experimental results can be satisfactorily explained by our stress-shadow model detailed below. First, we obtain an expression for the "sidewall" shear stress $\left(\sigma_{\text {sidewall }}\right)$ on a plane perpendicular to the basal sliding plate and parallel to the sliding direction (see Supplementary Material):

$$
\sigma_{\text {sidewall }}=\mu_{b} \rho g y
$$

where $\mu_{b}$ is the measured coefficient of friction of the experimental materials against the basalsliding plate covered in sandpaper (Table 1), and $y$ is the axis parallel to the basal-sliding plate but orthogonal to the sliding direction. We set $y=0$ at the center of the basal-sliding plate (Figs. 4a and 4b). The relationship in equation (15) states that the sidewall shear stress depends on the coefficient of basal friction and the density of the experimental material; it increases with its distance from the central dividing line of the sliding plate.

Although $\sigma_{\text {sidewall }}=\mu_{b} \rho g y$ goes to infinite as $y \rightarrow \infty$, the induced shear stress parallel to the newly created Riedel shears $\left(\sigma_{f p}\right)$ is finite. Evaluation of this value at $y=d$, which marks the edge of the Riedel shear zone (Fig. 4a), involves a transformation of coordinates that leads to the following expression for the effective fault-parallel shear stress $\left(\sigma_{f p}\right)$ :

$$
\sigma_{f p}=\mu_{b} \rho g d \cos (2 \theta)
$$

where $d$ is a distance measured along the $y$-axis (Fig. 4a) such that $\sigma_{f p}(y=d)$ is greater than the yield strength of the experimental materials and $\theta$ is the angle between the basal-shear direction and the Riedel shear orientation ( $16^{\circ}$ in our experiments) (Figs. 4b and 4c) (Jaeger et al., 2009; Supplementary Material). 


\section{Continental strike-slip faults}

We determine the average spacing of active strike-slip faults in the India-Asia collisional orogen and across the San Andreas transform boundary in California (Fig. 1). Application of the stress-shadow model (i.e., equation [12]) to crustal-scale strike-slip faults requires knowledge of the brittle-crust thickness (i.e., $h$ in Fig. 3) and coefficient of internal friction $\left(\overline{\mu_{\varphi}}\right)$. The latter parameter is well constrained from experimental rock mechanics (Jaeger et al., 2009). We estimate brittle-crust thickness by identifying the seismogenic zone thickness $(L)$ using highprecision relocated earthquake data from Asia and California.

\subsection{Strike-slip faults in California and Asia}

Four domains of active parallel strike-slip faults were investigated along the San Andreas system in California (e.g., Dickinson, 1996) and across the India-Asia collision zone (e.g., Yin, 2010) (Fig. 1). Spacing between the faults was measured perpendicular to the fault strike. The average and standard deviation for fault spacing within each domain are given in Table 2.

Strike-slip fault domains are observed on either side of the San Andreas fault (e.g., Dickinson, 1996) (Fig. 1a). In central California near San Francisco, four right-slip faults are parallel to the San Andreas fault (e.g., Savage and Lisowski, 1993), including the Hayward, Calaveras, and Greenville faults from west to east. These faults have an average fault spacing of $33 \pm 3 \mathrm{~km}$ (Fig. 1c). In southern California west of the San Andreas fault, nine north-striking right-slip faults extend from the Western Transverse Range in the north through the borderland region in the south. These faults have an average fault spacing of $47 \pm 15 \mathrm{~km}$ (Fig. 1c), and are the Ferrelo, San Clemente-San Isidro, Newport-Inglewood-Rose Canyon, Elsinore, and San Jacinto faults, from west to east (e.g., Dickinson, 1996). East of the San Andreas fault in 
375 southern California, the Eastern Transverse Range is comprised of six west-striking left-slip

376 faults: Mammoth Wash-Black Eagle, Salton Creek-Aztec Mines Wash, Chiriaco, Smoke Tree

377 Wash-Victory Pass, Blue Cut, and Pinto Mountain fault zones (e.g., Dickinson, 1996). These

378 faults have an average spacing of $20 \pm 8 \mathrm{~km}$ (Fig. 1c). Also east of the San Andreas fault but

379 north of the left-slip Pinto Mountain fault, there are eight north-striking right-slip faults in the

380 Mojave domain (Fig. 1a) with an average spacing of $16 \pm 2 \mathrm{~km}$ (Fig. 1c). They are, from west to 381 east, the Helendale, Lockhard-Lenwood, Gravel Hills-Camp Rock, Blackwater-Calico, Pisgah-

382 Bullion, Ludlow, Bristol Mountain, and Granite Mountain faults (Dokka and Travis, 1990).

383 Active intra-continental deformation in Asia is the combined result of continental

384 collision in the south and oceanic subduction in the east (e.g., Yin, 2010). A series of active

385 right-slip faults occur in central Asia (e.g., Yin, 2010) (Fig 1b). These faults, dispersed from the

386 Caspian Sea in the southwest to the southern edge of Lake Baikal in the northeast, have an

387 average fault spacing of $407 \pm 99 \mathrm{~km}$ (Fig. 1d). Three active east-striking left-slip faults, with an

388 average fault spacing of $178 \pm 53 \mathrm{~km}$ (Fig. 1d), are present across the northern Tibetan Plateau

389 (Fig. 1b): the Kunlun, Qinling, and Haiyuan faults (e.g., Taylor and Yin, 2009; Zuza and Yin,

390 2016). The V-shaped conjugate strike-slip faults of central Tibet (Taylor and Yin, 2009; Yin and

391 Taylor, 2011) consist of left-slip faults in the north that merge with right-slip faults to the south

392 (Fig. 1b). The average spacing of these conjugate faults is $92 \pm 24 \mathrm{~km}$ (Fig. 1d). In Iran, parallel

393 and active north-northwest-striking right-slip faults (Bachmanov et al., 2004) (Fig. 1b) have an

394 average spacing of $139 \pm 50 \mathrm{~km}$ (Fig. 1d).

395

396

397 


\subsection{Seismogenic zone thickness observations}

Relocated earthquake location data were compiled for California (Schaff and Waldhauser, 2005; Lin et al., 2007; Waldhauser and Schaff, 2008; Hauksson et al., 2012), Central Asia (Chu et al., 2009; Sloan et al., 2011), Tibet (Chu et al., 2009; Sloan et al., 2011), and Iran (Chu et al., 2009; Sloan et al., 2011; Maggi et al., 2000). Earthquake location data from central California encompasses events from 1984 to 2011 that were relocated by waveform cross correlation and double-difference methods (Schaff and Waldhauser, 2005; Waldhauser and Schaff, 2008). Reported vertical depth errors are less than $0.7 \mathrm{~km}$ at $95 \%$ confidence.

Earthquakes events from 1981 to 2011 are compiled in the southern California earthquake database of Lin et al. (2007) and Hauksson et al. (2012). The relative and absolute vertical depth errors are reported to be less $0.1 \mathrm{~km}$ and $1.25 \mathrm{~km}$, respectively, at $90 \%$ confidence. In Asia, teleseismically relocated earthquake-location data span events from 1977 to 1998 (Maggi et al., 2000), 1990 to 2005 (Chu et al., 2009), and 1965 to 2009 (Sloan et al., 2011). Reported vertical errors are < 1 km (Chu et al., 2009) and < 4km (Maggi et al., 2000; Sloan et al., 2011).

The compiled earthquake events and their focal depths are plotted in Figure 6. We seek the base of the seismogenic zone, and ultimately the brittle-crust thickness, from each strike-slip fault domain (Fig. 1). Seismic events from the stronger bounding regions, where strike-slip faulting is not observed, were also examined (Fig. 6) to constrain $\alpha$. We avoid earthquakes at mantle depths whose occurrences may have been associated with continental subduction, especially near the Pamirs and Tian Shan (Burtmann and Molnar, 1993).

Events from each domain were projected onto a vertical plane perpendicular to the strikeslip faults (Fig. 6). Plots of earthquake depth versus horizontal distance along this perpendicular plane are shown in Figure A3, for which the cutoff depth above which 95\% (D95) and 90\% 
421 (D90) seismicity was calculated (Table 2). This was done in several segments along each profile

422 and their average value defines the seismogenic zone thickness (Fig. A3). Specifically, we use

423 segment length of $25 \mathrm{~km}$ for Californian faults and 500 to $1000 \mathrm{~km}$ for Asian faults (Fig. A3).

424 The longer segment length for Asian domains reflects the sparse seismic data. Our results show

425 that average fault spacing in California and Asia (Fig. 1) is linearly proportional to the

426 seismogenic zone thickness (Fig. 7a) (Table 2), with a steeper slope for the data from Asia and

427 negative vertical-axis intercepts for both datasets.

428

429

\section{Discussion}

Observations from our analogue experiments and crustal-scale strike-slip faults reveal a

431 fundamental observation that fault spacing $(S)$ is linearly proportional to brittle-layer thickness

432 (h). Our physical models show this relationship to hold for experiments with solely frictional

433 materials (Fig. 4d) and for two-layer experiments with a viscous layer underlying frictional

434 materials (Fig. 4e).

435

\subsection{Minimum and maximum thickness cutoffs for generating strike-slip faults}

In our analogue experiments, strike-slip faults were only generated when the thickness of

438 the frictional materials was between $\sim 1$ and $\sim 7 \mathrm{~cm}$ (Fig. 4), which suggests that a minimum $\left(h_{0}\right)$

439 and maximum $\left(h_{\max }\right)$ brittle-layer cutoff thicknesses exist for generating strike-slip faults. The

440 regressions of continental $S$ versus $h$ yield negative vertical-axis intercepts for both the Asian and

441 Californian datasets (Fig. 7a). The simplest explanation for these negative intercepts is that there

442 is a minimum cutoff thickness for nucleating continental strike-slip faults. As previously

443 discussed (section 4.2), the boundary conditions that drive strike-slip faulting in the analogue 
444 experiments are different from those assumed in the derivation of our stress-shadow model.

445 Thus, the brittle-layer cutoff thickness values for each setting require different explanations.

446 In our stress-shadow model for crustal-scale strike-slip faulting, the regional shear stress

$447\left(\sigma_{s}^{r}\right)$ and shear fracture strength $(\bar{Y})$ increase linearly with depth $(h)$. The two quantities also

448 have intercepts at the surface $(h=0)$, with their values equal to $C_{0}$ and $C_{2}$ as defined in equations

449 (7) and (9). Although we assume $C_{0}=C_{2}$ in our stress-shadow derivation, their difference may

450 explain the minimum cutoff value for the observed fault spacing in continental settings (Fig. 7a).

451 Given that the regional shear stress $\left({\sigma_{s}}^{r}\right)$ and shear fracture strength $(\bar{Y})$ also have different

452 slopes, these two lines must intersect in the ${\sigma_{s}}^{r}$ and $\bar{Y}$ vs. $h$ plot (Fig. 8a). Thus, the portion of

453 the shear stress curve below the strength curve defines the value for the minimum fault-spacing

454 cutoff (i.e., $h_{0}$ in Fig. 8a). Although the above explanation may apply to crustal-scale strike-slip

455 faults, it is clearly not applicable to the occurrence of strike-slip faults whose spacing is on the

456 order of $10 \mathrm{~s}$ to $100 \mathrm{~s} \mathrm{~m}$. These smaller scale faults are not controlled by the thickness of the

457 brittle crust but rather local bedding thickness and/or reactivation of pre-existing factures as

458 commonly observed at outcrop scales (e.g., Aydin and Johnson, 1978; Segall and Pollard, 1983;

459 Martel and Pollard, 1989).

460 In our analogue experiments, the effective fault-parallel shear stress $\left(\sigma_{f p}\right)$ is not depth-

461 dependent (Fig. 8c) (see section 4.2 and Supplementary Material). However, the vertically

462 averaged shear fracture strength $(\bar{Y})$ of the sand/crushed walnut shells in our experiments does

463 vary with $h$ (Fig. 8c). For lower brittle-layer thickness values $(h<\sim 7 \mathrm{~cm}), \sigma_{f p}$ is greater than $\bar{Y}$

464 and parallel strike-slip faulting occurs (Fig. 8d). When $h$ exceeds some critical thickness (i.e.,

$465 h_{\max }$ in Fig. 8c), the shear fracture strength $\bar{Y}$ surpasses the fault-parallel shear stress $\sigma_{f p}$ (i.e.,

$466 \bar{Y}>\sigma_{f p}$ ), and Riedel-shear fracturing is suppressed (Fig. 8d). 

thickness is $<\sim 1 \mathrm{~cm}$ for sand and $<\sim 3 \mathrm{~cm}$ for crushed walnut shells (Fig. 5d). The fact that this minimum thickness, $h_{\min }$, varies for different density materials indicates that the vertical stress

470 must play a controlling role in determining the condition that favors strike-slip faulting. We

471 tentatively suggest that the reduction of the sand/crushed walnut shell thickness leads to a switch

472 of the principal stress directions, from $\sigma_{2}$ being vertical for the strike-slip regime when $h>h_{\min }$ to $473 \sigma_{2}$ being horizontal for dip-slip fault regime when $h<h_{\min }$. We further interpret that the inferred 474 dip-slip faulting may be blind and concentrated immediately above the sliding-plate surface at 475 the base of the experimental materials. Given the brittle-layer thickness uncertainties of $\sim 1 \mathrm{~mm}$, 476 any blind structures would have been indiscernible at the surface during the smallest thickness 477 experiments. used to further verify the stress-shadow model. At $h=h_{\max }, \bar{Y}=\sigma_{f p}$ which requires

$$
C_{0}+\frac{1}{2} \mu_{\varphi} \rho g h_{\max }=\mu_{b} \rho g d \times \cos 2 \theta
$$

481 The maximum cutoff thickness for the sand and crushed walnut shell experiments were $\sim 6 \mathrm{~cm}$ 482 and $\sim 7 \mathrm{~cm}$ respectively. By incorporating the frictional properties of the experimental materials 483 (Table 1) into equation (18), we can estimate $d$. For both the sand and crushed walnut shell 484 experiments, the calculated $d$ value is $\sim 0.04 \mathrm{~m}$. Figures $4 \mathbf{b}$ and $4 \mathbf{c}$ show that the boundaries of 485 Riedel shear zones are 2-4 cm from basal-sliding plate center, which corroborates this result. 
sliding layer $\left(h_{f}\right)$ and a transitional zone $\left(h_{f v}\right)$ of frictional sliding and viscous creeping (Fig. 3), such that $L=h_{f}+h_{f v}$. This diffuse brittle-ductile transition zone should have a maximum thickness of a few kilometers. Assuming that $h_{f v}$ is relatively constant globally, a systematic overestimation of the brittle-crust thickness $\left(h=h_{f}\right)$ by several kilometers in both Asia and California (Fig. 7) would affect the vertical-axis intercept of the $S$ - $h$ linear regression but the $S / h$ slope should remain the same.

In addition, the fault cohesive strength may be locally greater than the crustal cohesive strength (i.e., $C_{l}>C_{0}$ ) due to fault healing effects (e.g., Tenthorey and Cox, 2006). Given equation (11), this condition would lead to a negative vertical-axis intercept on a $S$ versus $h$ plot (e.g., Fig. 7a). This seems counterintuitive but may be applicable to Asia and California where penetrative fracturing, expressed by the widespread off-fault seismicity (e.g., Chu et al., 2009; Hauksson, 2011), may have reduced the cohesive strength of the deforming crust. That is, the actively forming fractures away from through-going faults are mostly isolated, creating dead pores that are less likely to be healed by chemical precipitation than the well-connected fracture networks in active fault zones after major rupture events (Tenthorey and Cox, 2006). Thus, we may rewrite the seismogenic thickness $L$ more completely as $L=\left(h^{\prime}+h_{\mathrm{FH}}\right)+h_{\mathrm{fv}}$, where $h^{\prime}$ is the effective brittle-crust thickness and $h_{\mathrm{FH}}$ is the pseudo brittle-crust thickness induced by fault healing. Only if $h_{F H}=h_{f v}=0$ does the seismogenic thickness $L$ equal the brittle-crust thickness $h^{\prime}=h$. Because the effects of fault healing and a diffuse brittle-crust transition counteract each other, and any healing effects must be minor because the strike-slip faults are still active, we reasonably assume that $L=h($ Fig. 7a). 


\subsection{Formation of irregularly-spaced strike-slip faults}

Northeast-striking right-slip faults in northern China are irregularly spaced at intervals ranging from $\sim 100 \mathrm{~km}$ in the west to $>500 \mathrm{~km}$ in the east (Yin et al., 2015). Equation (12) implies that irregularly spaced faults may be generated if the (a) strengths of the parallel faults are different, (b) fault-bounded crust has spatially varying shear strengths, and/or (c) thickness of the fault-hosting layer varies in laterally. The seismogenic thickness across North China varies from $\sim 20 \mathrm{~km}$ in the west to $>30 \mathrm{~km}$ in the east (Wang et al., 2013), which correlates with closer fault spacing in the west (Yin et al., 2015). Alternatively, spatially varying crustal strength or fault strength may locally affect faulting in northern China.

Related to such heterogeneities, the role of preexisting weaknesses in controlling fault spacing should not be underestimated. Major fault systems will inevitably exploit preexisting weaknesses (e.g., Segall and Pollard, 1983; Martel and Pollard, 1989) but an overarching fundamental mechanism controls the observed even spacing of active crustal-scale strike-slip faults (Fig. 1). Although the strike-slip faults in northern Tibet parallel Phanerozoic sutures (Zuza and Yin, 2016) and some of the strike-slip faults in California exploit preexisting normal faults (Dokka, 1989), most of the parallel strike-slip faults discussed here crosscut the regional structural trend (Fig. 1).

\subsection{Role of the lower crust driving strike-slip faulting}

Regional shear stress $\sigma^{b c}$ (or ${\sigma_{S}}^{r}$ ) is a key parameter that drives faulting in the stressshadow model (Fig. 3). In our derivation for continental strike-slip faults we assumed that $\sigma_{s}{ }^{r}$ equals $\overline{Y^{B R}}$ (Fig. 3). Alternatively, distributed basal shear in a viscous lower crust may drive or influence the regional shear stress $\sigma_{s}{ }^{r}$ acting on the brittle crust (e.g., Roy and Royden, 2000a, 
2000b). Our sand-putty analogue experiments demonstrate how the rheological and/or geometric

537 properties of the underlying viscous layer may affect brittle-layer fault spacing.

Interpretation of the two-layer brittle-viscous experiments is not as straightforward as the

539 single-brittle-layer experiments. In section 4.2 we showed that although the boundary conditions

540 for our experimental setup are different from our theoretical model (e.g., Fig. 3 vs. Fig. 4), the

541 derived fault-parallel shear stress in our experiments, $\sigma_{f p}$, is equivalent to the regional shear

542 stress, $\sigma^{b c}$, of Figure 3. The single-layer brittle-material experiments involved rate-independent

543 frictional materials and a constant basal-sliding-plate velocity throughout all trials. This allows

544 for investigation of the brittle-layer thickness versus fault spacing relationship (i.e., the $S / h$

545 correlation in Fig. 4d) and direct comparison of the experiments and our theoretical model,

546 without extra variables such as loading rate (i.e., basal-sliding-plate velocity). However, the

547 brittle-viscous experiments involved a rate-dependent viscous-putty-layer with variable

548 thicknesses and viscosities (Fig. 4e). Although all trials used a constant basal-sliding-plate

549 velocity, the thickness and viscosity variations of the putty layer in these trials inversely and

550 directly affected, respectively, the basal stress acting on the overlying frictional-sand layer. Thus,

551 even with a constant basal-sliding-plate velocity, the basal loading rate acting on the sand layer

552 varied for experiments with different putty thicknesses and viscosities, and therefore direct

553 quantitative comparison between the putty-layer experiments is not possible. In viewing Figure

554 4e, we emphasize that the three sets of trials with similar viscosities and putty thicknesses

555 involve minor differences in different basal loading rates. Even though the time-dependent

556 viscous layer complicates our analysis, the linear $S / h$ relationship for each set of trials with

557 similar initial conditions (e.g., putty thickness or viscosity) gives us some confidence that our 
results provide meaningful qualitative insight into how an underlying viscous layer affects deformational processes in the overlying frictional layer.

The viscous putty may affect the $S / h$ slope in the overlying brittle layer in several ways: (1) the viscosity and/or thickness of the putty controls the basal shear stress acting on the brittle materials, (2) distributed basal loading causes a variable-width basal shear zone, and/or (3) the frictional interaction at the sand-putty interface affects the basal-shear stress acting on the overlying brittle materials (i.e., coupling between the viscous and brittle layers). As described below, these first two scenarios do not appear to dominantly control fault spacing in the overlying brittle layer.

The viscosity and thickness parameters of the viscous putty should be proportional and inversely proportional to the maximum basal shear stress driven by motion within the underlying viscous material, respectively. Experiments with thicker and/or lower viscosity putty will have a lower possible basal shear stress, whereas thinner and/or higher viscosity putty layer should generate a higher basal shear stress. Figure 4e shows the results of our trials using putty layers with different viscosities and thicknesses. If these viscous-layer properties directly affect brittlelayer fault spacing, then the observed $S / h$ slope should vary systematically according to our stress-shadow model. That is, thicker and/or lower viscosity putty trials (i.e., lower basal shear stress) should have a steeper $S / h$ relationship, whereas thinner and/or higher viscosity putty experiments (i.e., higher basal shear stress) should result in a shallower $S / h$ slope (e.g., Figs 3 and 5). Our experiments do not show these systematic variations (Fig. 4e). The thicker/less viscous putty experiments yield the shallowest $S / h$ slopes (i.e., blue squares in Figure 4e). Conversely, the thinner and/or more viscous putty experiments yield steeper $S / h$ slopes (i.e., green and red symbols in Figure 4e). 
582 (see section 4.2 and Supplementary Material), fault-parallel shear stress $\left(\sigma_{f p}\right)$ is a function of $d$ 583 and $\mu_{b}$ as in equation (16). If distributed basal loading affects brittle-layer fault spacing, we 584 would expect that the viscous-layer experiments would involve relatively distributed basal shear 585 when compared to the granular material-only trials. This would lead to a decreased $d$ value in 586 equation (16) and thus an increased $S / h$ slope, which is not observed (Fig. 4e). The coefficient of friction between the sand and putty (i.e., $\mu_{b}$ of equation [16]) is 0.73 , which is higher than for sand against sand paper (Table 1). The higher $\mu_{b}$ for the sand-putty experiments should lead to a reduced $S / h$ slope, which is observed in the sand-putty experiments (Fig. 4e). Furthermore, all else being equal, equation (16) predicts that given the measured $\mu_{b}$ 591 values for each set of experiments (Table 1), the sand-only experiments will have a $S / h$ slope 592 that is $\sim 1.3$ times that of the sand-putty experiments. This slope difference is observed: the 0.68 $S / h$ slope for the sand-only experiments is $\sim 1.2-1.3$ times the $\sim 0.52$ slope for the sand-putty 594 experiments (Figs. 4d and 4e). These results suggest that the friction coefficient at viscous595 brittle layer interface (i.e., the coupling between the two layers) affects the strike-slip fault 596 spacing in the brittle layer more than the effects of the distributed basal shear by the viscous 597 layer or the rheological variations of this viscous layer. These findings contrast the viscoelastic models of Roy and Royden (2000a, 2000b).

Although we present a linear stress-shadow model, our general solution can be modified for other values of $m$ and $n$. For example, the addition of a viscous layer may make our assumed 601 simple linear relationship more complex, and future work is needed to explore other possible 602 nonlinear solutions that may ultimately be useful for understanding the shear-stress distribution 603 in two-layer viscous-brittle systems. However, we assert that the observed linear relationship 
604 between fault spacing and brittle-layer thickness in both our analogue experiments and crustal605 scale strike-slip faults validates our application of a linear stress-shadow model to continental 606 strike-slip faults.

607

6.5 Estimates of absolute fault friction from fault spacing and seismogenic zone thickness

The observed difference in $S / h$ slope between Asia and California must reflect differences 610 in how the faults interact with one another and with the fault-bounded crust. Based on equation

611 (12) and assuming that the crustal internal coefficient of friction $\overline{\mu_{\varphi}}$ for both continents is the 612 same, the steep $S / h$ slope observed in Asia may result from a lower magnitude of effective fault 613 friction $\left(\overline{\mu_{f}}\right)$, a higher magnitude regional shear stress, or a combination of factors. In California, the seismogenic thicknesses of the relatively stable Western Transverse and 615 Central Valley-Sierra regions were compared with the $L$ values of the adjacent deforming 616 regions (Fig. 6) to estimates $\alpha=H / h$ values of 1.05 to 1.2 . Using regionally averaged $\alpha=1.1$ 617 and $\overline{\mu_{\varphi}}=0.24$ values, we find that the closely spaced faults in the eastern San Andreas fault 618 system are stronger at $\overline{\mu_{f}}=0.18-0.22$ than the widely spaced faults in the western San Andreas 619 fault system at $\overline{\mu_{f}}=0.15-0.18$ (Fig. 7b). Because of the sparser data in Asia, we are unable to 620 resolve between the internal variation of seismogenic zone thickness in a single strike-slip 621 domain $(h)$ and its difference from the seismogenic zone thickness of its bounding regions $(H)$. 622 We take this to indicate $\alpha=H / h \approx 1.0$. Available earthquake data near the edges of the central 623 Asia strike-slip domain yield an $\alpha$ value of $\sim 1.03$. Using this value for all the strike-slip systems 624 in Asia, we find their strength to be weaker $\left(\overline{\mu_{f}}=\sim 0.10-0.20\right)$ than the fault strength in the San 625 Andreas system $\left(\overline{\mu_{f}}=0.15-0.21\right)$ (Figs. 7b and 7c). The weak faults in Asia and relatively 626 stronger faults in California are consistent with fault-strength studies (e.g., Bird and Kong, 1994; 
627 Vernant and Chéry, 2006; Fay and Humphreys, 2006; Humphreys and Coblentz, 2007; He and

628 Chéry, 2008). Note that if our assumption of $n=m=1$ in equation (4) is incorrect, and these

629 values both equal 2 (i.e., similar to the LEFM stress-distribution solution), then the

630 corresponding $\overline{\mu_{f}}$ estimates for faults in both California and Asia would decrease; all would be < $631 \quad 0.10$.

632

The San Andreas transform fault boundary and Asia both experience large strike-slip

633 earthquakes (Figs. 1a and 1b). The relatively weak faults in Asia (Fig. 7c) may explain the long-

634 puzzling observation that active deformation induced by the indentation of India extends $\sim 3500$

635 km north of the Himalaya (Fig. 1b). Specifically, the weakest faults in Asia (i.e., in Central Asia

636 and northern Tibet) (Fig. 7c) are also the furthest from the India-Asia collisional front, which

637 permits intra-continental deformation to occur within the Asian interior. The slippery faults in

638 Asia make them sensitive to minor changes in crustal stress magnitude, which explains why the

639 Asian interior is prone to large $(M>7.0)$ devastating strike-slip earthquakes (Fig. 1b). The

640 weaker faults in both locations can be readily explained by their hosting crustal compositions

641 containing friction-reducing clays and hydrated phyllosilicates (e.g., Collettini et al., 2009):

642 central Asia is dominated by flysch complexes (e.g., Sengör et al., 1993) and the western San

643 Andreas system is dominated by mélange and forearc materials (e.g., Dickinson, 1981).

644 Constraining fault strength is critical in modeling continental deformation (Bird and Kong, 1994)

645 and earthquake mechanics (Console et al., 2015), and this work provides an additional method of 646 estimating this critical parameter.

647

648

649 
650

651

652 brittle-layer thickness in nature and scaled analogue experiments. Specifically, this relationship

653 can be quantified as a function of brittle-crust thickness, fault strength, and regional stress state

654 with our newly developed stress-shadow model. The application of this model using seismogenic

655 zone thickness and fault spacing reveals that the closely spaced faults in the eastern San Andreas

656 system are stronger than the widely spaced faults in the western San Andreas system.

657 Furthermore, we find that the average friction coefficient of active strike-slip faults in the India-

658 Asia collision orogen is lower than that of faults in the San Andreas transform system.

659

\section{Acknowledgements}

661 We thank two anonymous reviewers for their critical comments and very constructive

662 suggestions that greatly improved the clarity and rigor of the model presented in this work.

663 A.Y.'s research on continental tectonics has been funded by grants from the Tectonics Program

664 of the National Science Foundation.

665

666

667

668

\section{Appendix A. Supplementary Material}

Supplementary material related to this article can be found online at nnn-AAA. 
672

\section{References}

Aydin, A., and Johnson, A. M., 1978, Development of faults as zones of deformation bands and as slip surfaces in sandstone: Pure and Applied Geophysics, v. 116, p. 931-942.

Bai, T., and Pollard, D. D., 2000, Fracture spacing in layered rocks: a new explanation based on the stress transition: Journal of Structural Geology, v. 22, no. 1, p. 43-57.

Bird, P., and Kong, X., 1994, Computer simulations of California tectonics confirm very low strength of major faults: Geological Society of America Bulletin, v. 106, no. 2, p. 159174.

Burtman, V. S., and Molnar, P., 1993, Geological and geophysical evidence for deep subduction of continental crust beneath the Pamir: Special Publication of the Geological Society of America, v. 291, p. 1-76.

Chu, R., Zhu, L., and Helmberger, D. V., 2009, Determination of earthquake focal depths and source time functions in central Asia using teleseismic P waveforms: Geophysical Research Letters, v. 36, no. 17.

Collettini, C., Niemeijer, A., Viti, C., and Marone, C., 2009, Fault zone fabric and fault weakness: Nature, v. 462, no. 7275, p. 907-910.

Console, R., Carluccio, R., Papadimitriou, E., and Karakostas, V., 2015, Synthetic earthquake catalogs simulating seismic activity in the Corinth Gulf, Greece, fault system: Journal of Geophysical Research: Solid Earth, v. 120, no. 1, p. 326-343.

Cruz, L., Teyssier, C., Perg, L., Take, A., and Fayon, A., 2008, Deformation, exhumation, and topography of experimental doubly-vergent orogenic wedges subjected to asymmetric erosion: Journal of Structural Geology, v. 30, no. 1, p. 98-115.

Davy, P., and Cobbold, P. R., 1988, Indentation tectonics in nature and experiment. 1. Experiments scaled for gravity: Bulletin of the Geological Institutions of Uppsala, v. 14, p. 129-141.

Dickinson, W. R., 1981, Plate tectonic evolution of the southern Cordillera. Relations of tectonics to ore deposits in the southern Cordillera: Arizona Geological Society Digest, v. 14, p. 113-135.

Dickinson, W. R., 1996, Kinematics of transrotational tectonism in the California Transverse Ranges and its contribution to cumulative slip along the San Andreas transform fault system: Geological Society of America Special Paper, v. 305, p. 1-46.

Dokka, R. K., 1989, The Mojave extensional belt of southern California: Tectonics, v. 8, no. 2, p. 363-390.

Dokka, R. K. and Travis, C. J., 1990, Late Cenozoic strike-slip faulting in the Mojave desert, California: Tectonics, v. 9, p. 311-340. 
Fay, N., and Humphreys, E., 2006, Dynamics of the Salton block: Absolute fault strength and crust-mantle coupling in Southern California: Geology, v. 34, no. 4, p. 261-264.

Fossen, H., Schultz, R. A., Shipton, Z. K., and Mair, K., 2007, Deformation bands in sandstone: a review: Journal of the Geological Society, v. 164, no. 4, p. 755-769.

Freund, R., 1974, Kinematics of transform and transcurrent faults: Tectonophysics, v. 21, no. 1, p. 93-134.

Hauksson, E., Yang, W., and Shearer, P. M., 2012, Waveform relocated earthquake catalog for southern California (1981 to June 2011): Bulletin of the Seismological Society of America, v. 102, no. 5, p. 2239-2244.

He, J., and Chéry, J., 2008, Slip rates of the Altyn Tagh, Kunlun and Karakorum faults (Tibet) from 3D mechanical modeling: Earth and Planetary Science Letters, v. 274, no. 1, p. 5058.

Hubbert, M. K., 1937, Theory of scale models as applied to the study of geologic structures: Geological Society of America Bulletin, v. 48, no. 10, p. 1459-1520.

Hubbert, M. K., 1951, Mechanical basis for certain familiar geologic structures: Geological Society of America Bulletin, v. 62, no. 4, p. 355-372.

Humphreys, E. D., and Coblentz, D. D., 2007, North American dynamics and western US tectonics: Reviews of Geophysics, v. 45, no. 3.

Jackson, J., McKenzie, D., Priestley, K., and Emmerson, B., 2008, New views on the structure and rheology of the lithosphere: Journal of the Geological Society, v. 165, no. 2, p. 453465.

Jaeger, J. C., Cook, N. G., and Zimmerman, R., 2009, Fundamentals of rock mechanics: John Wiley \& Sons.

Lachenbruch, A. H., 1961, Depth and spacing of tension cracks: Journal of Geophysical Research, v. 66, no. 12, p. 4273-4292.

Lin, G., Shearer, P. M., and Hauksson, E., 2007, Applying a three-dimensional velocity model, waveform cross correlation, and cluster analysis to locate southern California seismicity from 1981 to 2005: Journal of Geophysical Research: Solid Earth, v. 112, no. B12.

Lister, G. S., and Davis, G. A., 1989, f: Journal of Structural Geology, v. 11, no. 1, p. 65-94.

Maggi, A., Jackson, J. A., Priestley, K., and Baker, C. A., 2000, A reassessment of focal depth distributions in southern Iran, the Tien Shan and northern India: do earthquakes really occur in the continental mantle?: Geophysical Journal International, v. 143, p. 629-661. 
Martel, S. J., and Pollard, D. D., 1989, Mechanics of slip and fracture along small faults and simple strike-slip fault zones in granitic rock: Journal of Geophysical Research: Solid Earth, v. 94, no. B7, p. 9417-9428.

Molnar, P., and Tapponnier, P., 1975, Cenozoic tectonics of Asia: effects of a continental collision: Science, v. 189, no. 4201, p. 419-426.

Naylor, M. A., Mandl, G. T., and Supesteijn, C. H. K., 1986, Fault geometries in basementinduced wrench faulting under different initial stress states: Journal of Structural Geology, v. 8, no. 7, p. 737-752.

Nur, A., Ron, H., and Scotti, O., 1986, Fault mechanics and the kinematics of block rotations: Geology, v. 14, no. 9, p. 746-749.

Pollard, D. D., and Segall, P., 1987, Theoretical displacements and stresses near fractures in rock: with applications to faults, joints, veins, dikes, and solution surfaces: Fracture mechanics of rock, v. 277, no. 349, p. 277-349.

Gross, M. R., 1993, The origin and spacing of cross joints: examples from the Monterey Formation, Santa Barbara Coastline, California: Journal of Structural Geology, v. 15, no. 6, p. 737-751.

Roy, M., and Royden, L. H., 2000a, Crustal rheology and faulting at strike-slip plate boundaries: 1. An analytic model: Journal of Geophysical Research: Solid Earth, v. 105, no. B3, p. 5583-5597.

Roy, M., and Royden, L. H., 2000b, Crustal rheology and faulting at strike-slip plate boundaries: 2. Effects of lower crustal flow: Journal of Geophysical Research: Solid Earth, v. 105, no. B3, p. 5599-5613.

Savage, J. C., and Lisowski, M., 1993, Inferred depth of creep on the Hayward fault, central California: Journal of Geophysical Research: Solid Earth, v. 98, no. B1, p. 787-793.

Schaff, D. P., and Waldhauser, F., 2005, Waveform cross-correlation-based differential traveltime measurements at the Northern California Seismic Network: Bulletin of the Seismological Society of America, v. 95, no. 6, p. 2446-2461.

Segall, P., and Pollard, D. D., 1983, Nucleation and growth of strike slip faults in granite: Journal of Geophysical Research: Solid Earth, v. 88, no. B1, p. 555-568.

Sengör, A. M. C., Natal'In, B. A., and Burtman, V. S., 1993, Evolution of the Altaid tectonic collage and Palaeozoic crustal growth in Eurasia: Nature, v. 364, p. 299-307.

Sibson, R. H., 1982, Fault zone models, heat flow, and the depth distribution of earthquakes in the continental crust of the United States: Bulletin of the Seismological Society of America, v. 72, no. 1, p. 151-163. 
Sloan, R. A., Jackson, J. A., McKenzie, D., and Priestley, K., 2011, Earthquake depth distributions in central Asia, and their relations with lithosphere thickness, shortening and extension: Geophysical Journal International, v. 185, no. 1, p. 1-29.

Swanson, M. T., 1988, Pseudotachylyte-bearing strike-slip duplex structures in the Fort Foster Brittle Zone, S. Maine: Journal of Structural Geology, v. 10, no. 8, p. 813-828.

Taylor, M., and Yin, A., 2009, Active structures of the Himalayan-Tibetan orogen and their relationships to earthquake distribution, contemporary strain field, and Cenozoic volcanism: Geosphere, v. 5, no. 3, p. 199-214.

Tchalenko, J. S., 1970, Similarities between shear zones of different magnitudes: Geological Society of America Bulletin, v. 81, no. 6, 1625-1640.

Tenthorey, E., and Cox, S. F., 2006, Cohesive strengthening of fault zones during the interseismic period: An experimental study: Journal of Geophysical Research: Solid Earth, v. 111, no. B9.

Vernant, P., and Chery, J., 2006, Low fault friction in Iran implies localized deformation for the Arabia-Eurasia collision zone: Earth and Planetary Science Letters, v. 246, no. 3, p. 197206.

Waldhauser, F., and Schaff, D. P., 2008, Large-scale relocation of two decades of Northern California seismicity using cross-correlation and double-difference methods: Journal of Geophysical Research: Solid Earth, v. 113, no. B8.

Wang, J., Dapeng, Z. and Yao, Z., 2013, Crustal and uppermost mantle structure and seismotectonics of North China Craton: Tectonophysics, v. 582, p. 177-187.

Yin, A., 2010, Cenozoic tectonic evolution of Asia: A preliminary synthesis: Tectonophysics, v. 488, no. 1, p. 293-325.

Yin, A., and Taylor, M. H., 2011, Mechanics of V-shaped conjugate strike-slip faults and the corresponding continuum mode of continental deformation: Geological Society of America Bulletin, v. 123, no. 9-10, p. 1798-1821.

Yin, A., Yu, X., Shen, Z. K., and Liu-Zeng, J., 2015, A possible seismic gap and high earthquake hazard in the North China Basin: Geology, v. 43, no. 1, p. 19-22.

Yin, A., Zuza, A. V., and Pappalardo, R. T., 2016, Mechanics of evenly spaced strike-slip faults and its implications for the formation of tiger-stripe fractures on Saturn's moon Enceladus: Icarus, v. 266, p. 204-216.

Zuza, A. V., and Yin, A., 2016, Continental deformation accommodated by non-rigid passive bookshelf faulting: An example from the Cenozoic tectonic development of northern Tibet: Tectonophysics, v. 677, p. 227-240. 


\section{FIGURE CAPTIONS}

806

807

808

809

810

811

812

813

814

815

816

817

818

819

820

821

822

823 824 (2016).

825

826

827

Figure 1. Evenly-spaced strike-slip domains in (a) California and (b) Asia and their average fault spacing. Inset in (a) shows parallel faults in central California. Histograms show fault spacing for each domain of strike-slip faulting in (c) California and (d) Asia. Locations (shown as yellow stars) and magnitudes of major intra-continental earthquakes along strike-slip faults in California and Asia: (1) $1857 \mathrm{M}=7.9$ Fort Tejon earthquake, (2) $1906 \mathrm{M}=7.8$ San Francisco earthquake, (3) $1992 \mathrm{M}=7.3$ Landers earthquake, (4) $1999 \mathrm{M}=7.1$ Hector Mine earthquake, (5) $1927 \mathrm{M}=$ 7.3 Lompoc earthquake, (6) $2001 \mathrm{M}=8.1$ Kunlun Pass earthquake, (7) $1932 \mathrm{M}=7.6$ Changma earthquake, (8) $1920 \mathrm{M}=7.8$ Haiyuan earthquake, (9) $1556 \mathrm{M}=8.0$ Shaanxi earthquake, (10) $1931 \mathrm{M}=8.0$ Fuyun earthquake, (11) $1957 \mathrm{M}=8.1$ Gobi Altai earthquake, (12) $1905 \mathrm{M}=8.4$ Bulnay earthquake, (13) $1679 \mathrm{M}=8.0$ Sanhe-Pinggu earthquake, (14) $1976 \mathrm{M}=7.8$ Tanshan earthquake, (16) $1966 \mathrm{M}=7.2$ Xingtai earthquake, (16) $1830 \mathrm{M}=7.5$ Cixian earthquake, and (17) $1668 \mathrm{M}=8.0$ Tancheng earthquake.

Figure 2. Conceptual model for the formation of evenly-spaced joints due to the stress shadow effect. (a) A layer under regional extension with a remote normal stress $\sigma_{n}={\sigma_{n}}^{r}$. (b) The presence of a fracture causes a local stress reduction and the stress-shadow effect prevents fractures from forming within the strength shadow, with length $S$. (c) This effect causes fractures in the deforming region to be spaced by this critical distance $S$. Figure is modified from Yin et al.

Figure 3. Model set up, model parameters, and boundary conditions for the formation of evenlyspaced strike-slip faults. Vertically uniform shear stress drives the formation of parallel strike- 
828 slip faults in a brittle layer. Off-fault shear stress $\sigma_{x z}$ satisfies the boundary conditions of $\sigma_{x z}(x=$

$8290)=\sigma^{f}$ and $\sigma_{x z}(\mathrm{x}=\infty)=\sigma^{b c}$. Parameters in the model: $\sigma^{f}$, shear stress on the fault; $\overline{\sigma^{f}}$,

830 vertically averaged shear strength of the fault; $\sigma^{b c}$, regional shear stress in the brittle crust; $S$,

831 stress-shadow length equal to fault spacing; $Y$ and $\bar{Y}$, shear fracture strength and vertically

832 averaged shear fracture strength of the deforming strike-slip fault domain; $\overline{Y^{B R}}$, vertically

833 averaged shear fracture strength of the stronger bounding region with a thickness $H$; $h$, brittle-

834 crust thickness in region of strike-slip faulting; $L$, seismogenic zone thickness that includes

835 regimes of frictional sliding $\left(h_{f}\right)$ and transitional frictional sliding and viscous creep $\left(h_{f v}\right) ; \alpha$

$836=H / h$. Coordinate system and sign convention are shown with red arrows.

837

838 Figure 4. (a) Plan view of experimental setup with 12-cm-wide basal sliding plate that is used to

839 create to create two parallel shear zones in which Riedel shears form. Note that the resulting

840 shear zone has a length and width of $M$ and $W_{s z}$, respectively. Also shown is the coordinate axis

841 and $d$ value, which measures the distance from the center of the basal-sliding plate to the Riedel-

842 shear zone (b) A representative experimental run showing the general apparatus setup and the

843 resulting development of nearly evenly-spaced parallel Riedel shear fractures in two parallel

844 distributed shear zones using crushed walnut shells $(h=30 \mathrm{~mm})$. The basal plate moved to the

845 right in this image, which created left- and right-slip shear zones in the top and bottom of the

846 image respectively. (c) Another representative experimental run with 7-mm-thick viscous putty

$847\left(h_{p}\right)$ overlain by dry sand $(h=20 \mathrm{~mm})$. The viscosity of the putty is $6.2 \times 10^{3} \mathrm{~Pa}$ s. The basal

848 plate in this image moved to the right. (d) Plot of fault spacing versus brittle layer thickness of

849 sand and crushed walnut shells obtained from this study for all experimental runs. The best-fit

850 linear regression is accomplished by forcing the lines through the origin. (e) Plot of fault spacing 
851 versus brittle layer thickness of sand underlain by viscous putty of different thicknesses and

852 viscosities. The best-fit linear regression is accomplished by forcing the lines through the origin.

853

854 Figure 5. Effects of model parameters on the relationship between fault spacing and brittle-crust 855 thickness as a function of (a) the difference between fault and crustal cohesive strengths $C_{0}-C_{1}$, 856 (b) $\alpha$ values, and (c) the effective fault friction $\overline{\mu_{f}}$.

858 Figure 6. Earthquake location data earthquake data from (a) California and (b) Asia. Domains of 859 evenly-spaced strike-slip faults with characteristic fault spacing are outlined. Calculation of 860 seismogenic zone thickness used the data outlined for each domain. The profile numbers 861 correspond to those shown in Figure A3. Data from Maggi et al. (2000), Schaff and Waldhauser 862 (2005), Lin et al. (2007), Waldhauser and Schaff (2008), Chu et al. (2009), Sloan et al. (2011), 863 and Hauksson et al. (2012).

865 Figure 7. (a) Plot of seismogenic zone thickness (using both D90 and D95 values) versus fault 866 spacing for Asia and California. The inset shows an enlarged plot of the California data. The 867 best-fit linear regressions for the seismogenic zone thickness data using either the D90 or D95 868 data show similar slopes. Note the negative vertical and positive horizontal intercepts for the 869 regression lines. (b-c) Relationship between fault spacing $(S)$ and brittle-crust thickness $(h)$ for 870 given $\alpha$ values. Plots for faults in (b) California use $\alpha=1.10$ and (c) Asia use $\alpha=1.03$. Other 871 parameters used in the plots are $\overline{\mu_{\varphi}}=0.24, \rho=3 \mathrm{~g} / \mathrm{cm}^{3}$, and $\left(C_{0}-C_{1}\right)=0 \mathrm{MPa}$. 
873 Figure 8. (a) Conceptual plot of dimensionless shear stress/strength versus brittle-crust thickness 874 showing the inferred minimum brittle-crust thickness $\left(h_{0}\right)$ cutoff for the formation of continental 875 strike-slip faults. Strike-slip faults will only be generated when the regional shear stress ${\sigma_{s}}^{r}$, 876 which is linearly proportional to $h$, exceeds the vertically integrated shear-fracture strength of the 877 material $(\bar{Y})$ at a critical brittle-curst thickness $h_{0}$. (b) Two scenarios for the continental strike878 slip faulting that highlight the concepts in (a). When the brittle-crust is too thin $\left(h<h_{0}\right)$, the 879 regional shear stress is not large enough to surpass the vertically averaged shear-fracture strength 880 of the crust, and no strike-slip faults are formed. When the brittle-crust thickness is greater than 881 the cutoff thickness, strike-slip faulting can occur. (c) Conceptual plot of dimensionless shear 882 stress/strength versus brittle-crust thickness showing the minimum $\left(h_{\min }\right)$ and maximum $\left(h_{\max }\right)$ 883 brittle-layer thickness cutoffs for strike-slip faulting in the analogue experiments. The depth884 independent fault-parallel shear stress $\left(\sigma_{f p}\right)$ intersects the depth-dependent shear-fracture 885 strength $(\bar{Y})$ curve at a critical thickness $h_{\max }$. Above this thickness value, strike-slip faulting is 886 suppressed by the strength of the material. Below some threshold thickness $h_{\min }$, strike-slip faults 887 are also not formed. (d) Three scenarios for strike-slip faulting in the analogue experiments.

888 When $h$ is too low, there is a switch of the principal stress directions, from $\sigma_{2}$ being vertical for 889 the strike-slip regime when $h>h_{\min }$ to $\sigma_{2}$ being horizontal for dip-slip fault regime when $h<h_{\min }$, 890 which results in blind thrusting and folding rather than strike-slip faulting. Additionally, when 891 the brittle layer is too thick $\left(h>h_{\max }\right)$, the vertically averaged shear strength $(\bar{Y})$ of the brittle 892 layer is greater than $\sigma_{f p}$, which suppresses strike-slip faulting. Strike-slip faulting does occur 893 when $h_{\min }<h<h_{\max }$. Note that the green arrows indicates the principal stress orientation. 
897 Table 1. Physical and mechanical properties of experimental materials.

\begin{tabular}{lllllllll} 
Material & $\begin{array}{l}\text { Density } \\
\left(\mathbf{k g} / \mathbf{m}^{\mathbf{3}}\right)\end{array}$ & $\begin{array}{l}\text { Grain } \\
\mathbf{s i z e}(\boldsymbol{\mu m})\end{array}$ & $\mathbf{\pm \sigma}$ & $\mathbf{C}_{\mathbf{0}}(\mathbf{P a})$ & $\mathbf{\pm \sigma}$ & $\boldsymbol{\mu}_{\boldsymbol{\varphi}}$ & $\mathbf{\pm \boldsymbol { \sigma }}$ & $\boldsymbol{\phi}(\mathbf{(})$ \\
\hline Sand & 1670 & 220 & 86 & 62.5 & 10.5 & 0.50 & 0.01 & 26.5 \\
Sand vs sandpaper & - & - & - & 51.5 & 40.5 & 0.53 & 0.03 & 28.1 \\
Sand vs putty/sand & - & - & - & - & - & 0.73 & 0.05 & 36.1 \\
Crushed walnut shells & 790 & 332 & 82 & 36.8 & 10.2 & 0.40 & 0.01 & 21.6 \\
Walnut shells vs sandpaper & - & - & - & 31.0 & 29.0 & 0.51 & 0.04 & 27.1 \\
$\mu_{\varphi}$, Coefficient of friction & & & & & & & & \\
$\phi$, Angle of friction & & & & & & & &
\end{tabular}

900 
Table 2. Observed fault spacing and seismogenic zone thickness.

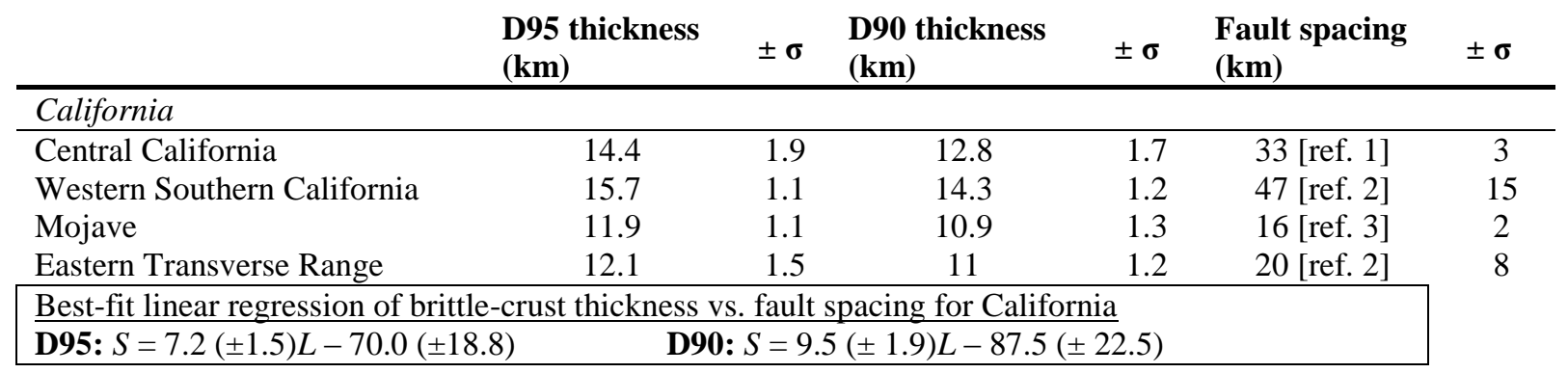

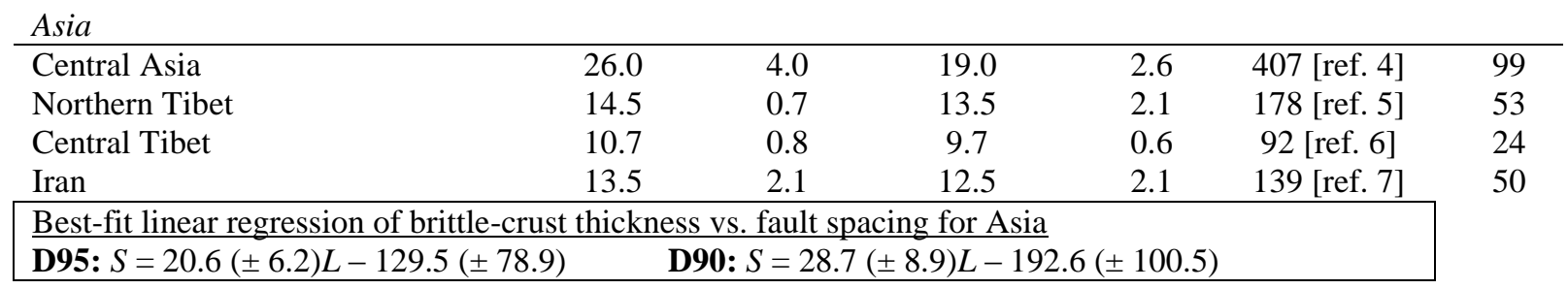

Sources: [ref. 1]: Savage and Lisowski (1993); [ref. 2]: Dickinson (1996); [ref. 3]: Dokka and Travis

903 (1990); [ref. 4]: Yin (2010); [ref. 5]: Zuza and Yin (2016); [ref. 6]: Yin and Taylor (2011) [ref. 7]:

904 Bachmanov et al., (2004). 

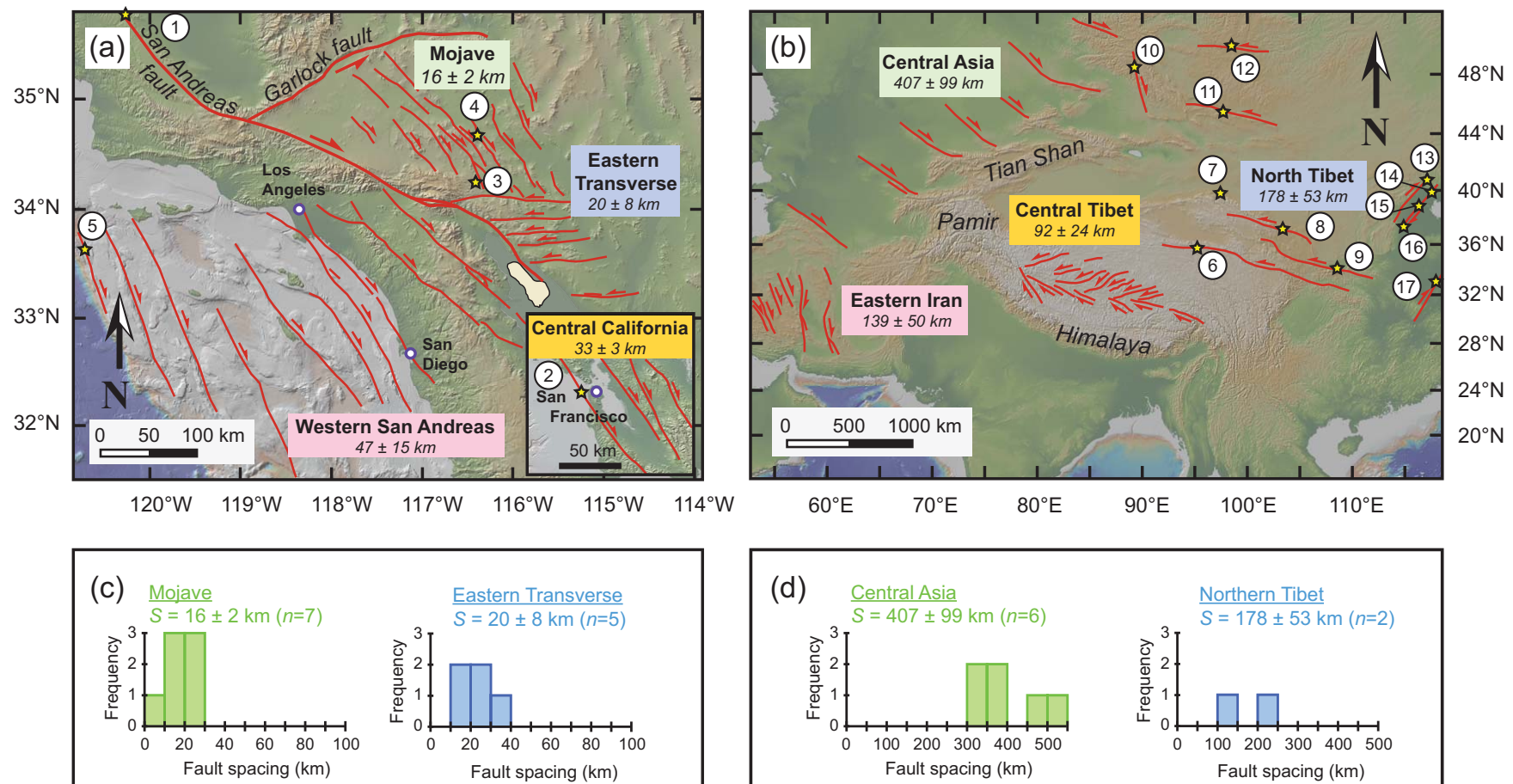

(d)
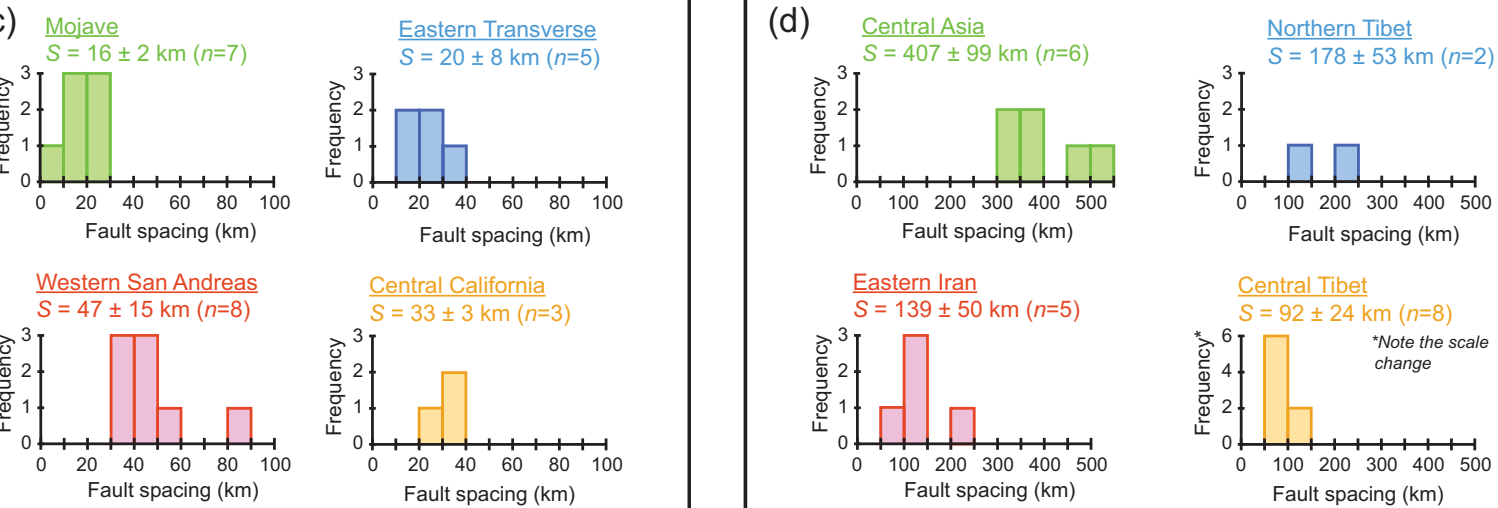

Eastern Iran
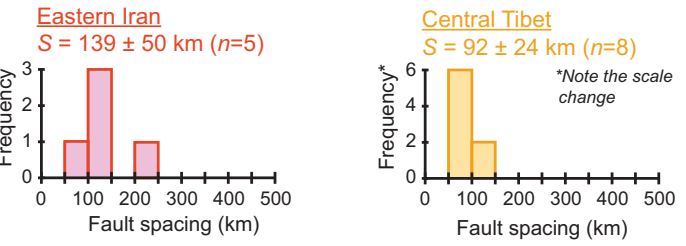

Zuza et al. - Figure 1 


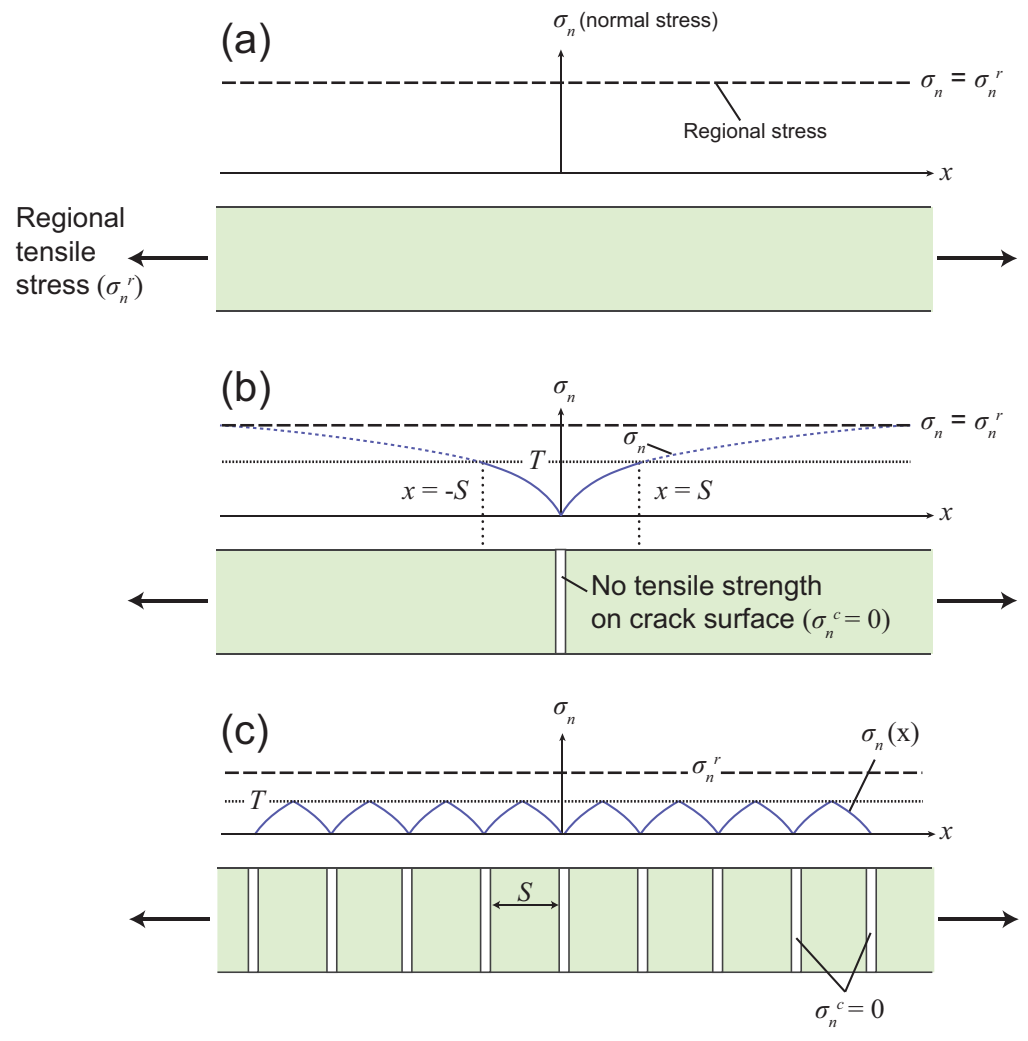

Zuza et al. - Figure 2 


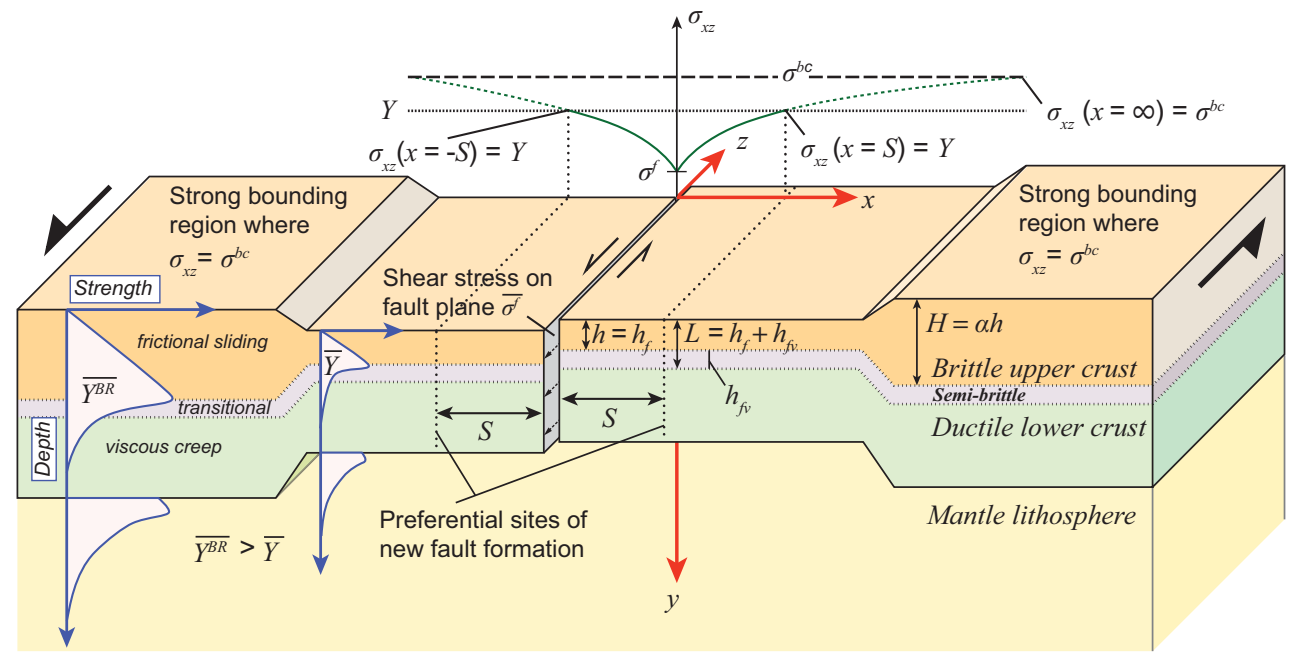

Zuza et al. - Figure 3 
(a)

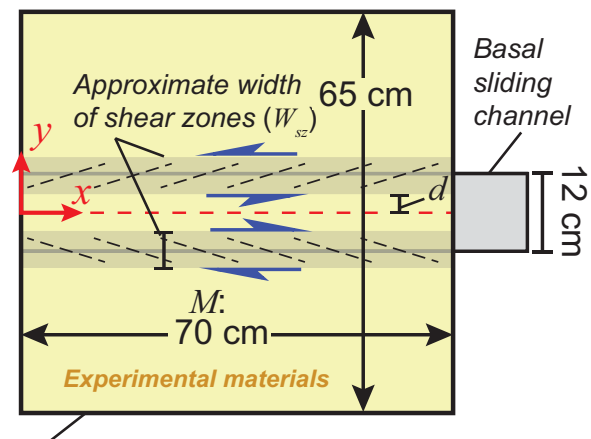

Fixed boundary walls

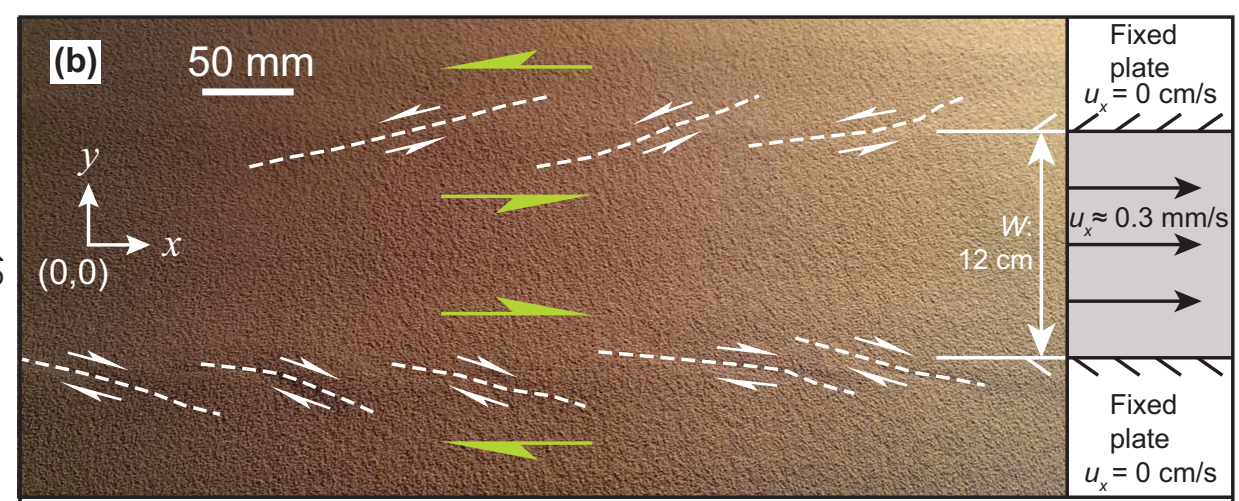

Trial 5 of 5 for crushed walnut shells with $30 \mathrm{~mm}$ thickness: $h: 30 \pm 1 \mathrm{~mm} \quad S: 27.3 \pm 5.7 \mathrm{~mm}$

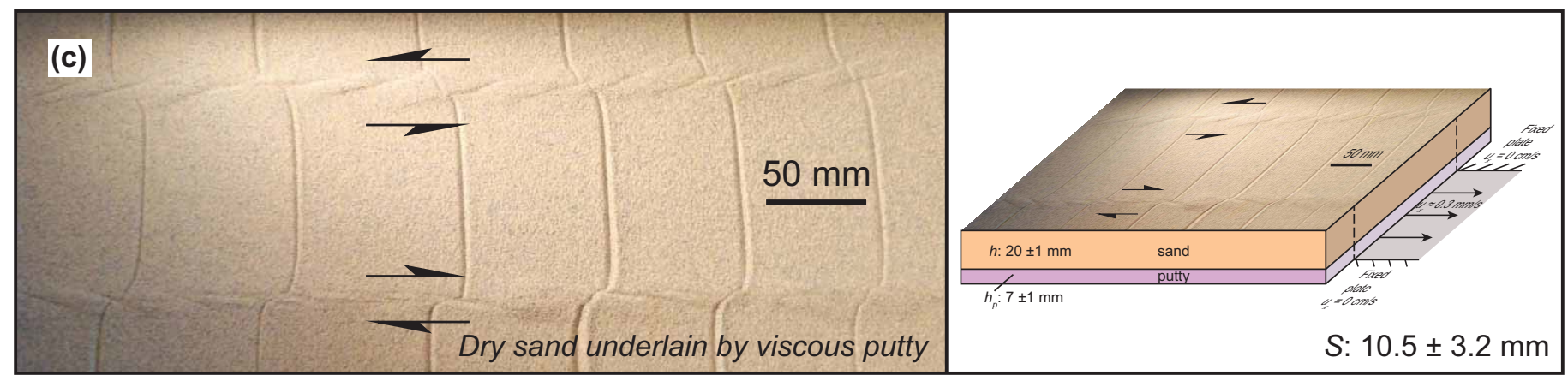

\section{(d) Dry granular materials}

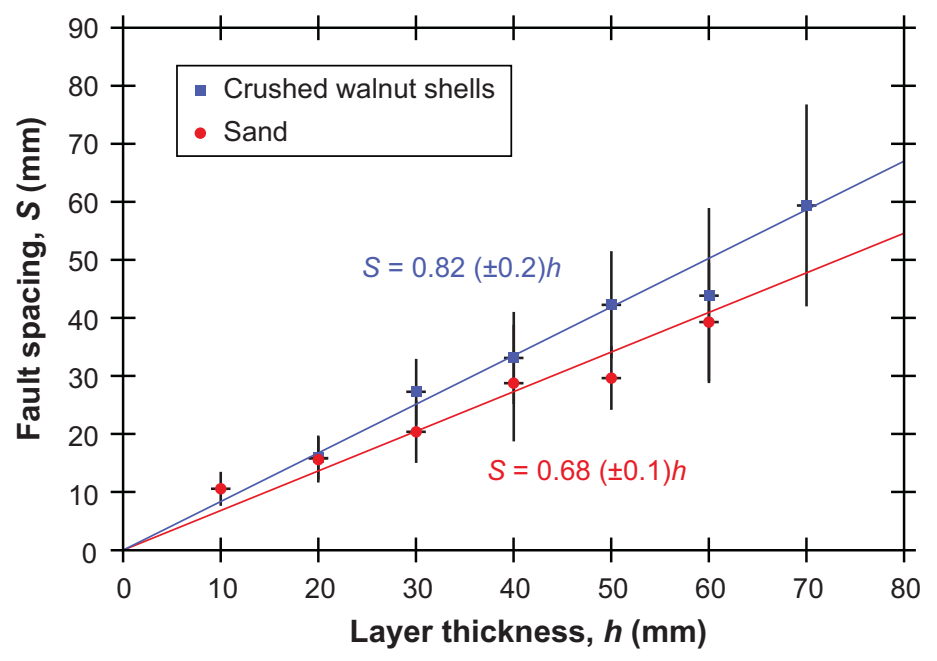

(e) Dry sand underlain by viscous putty

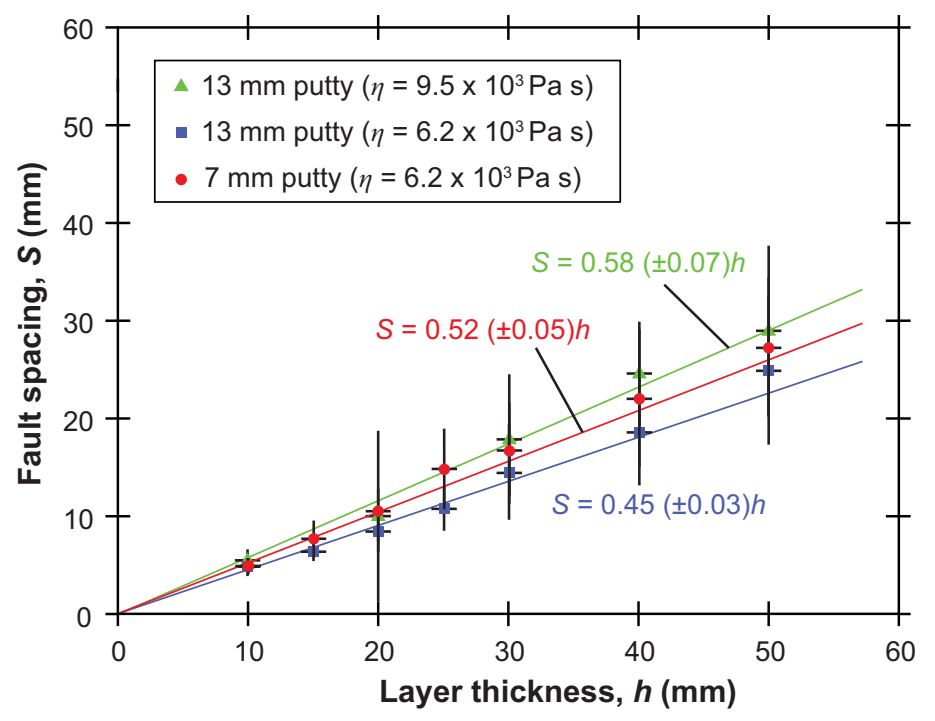


(a)

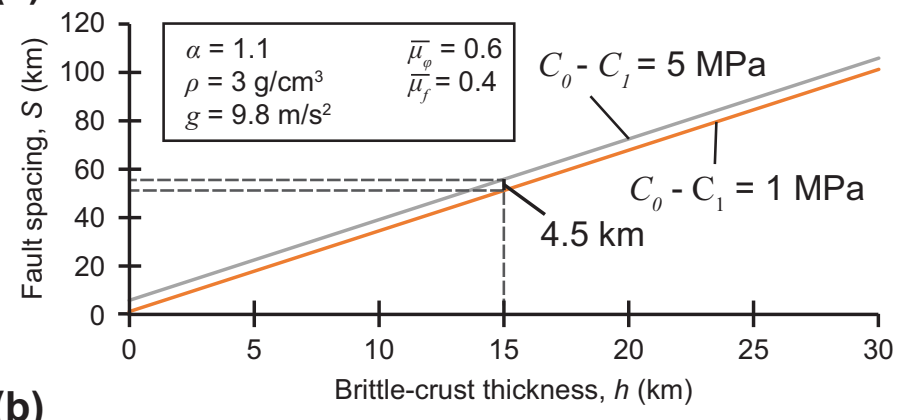

(b)

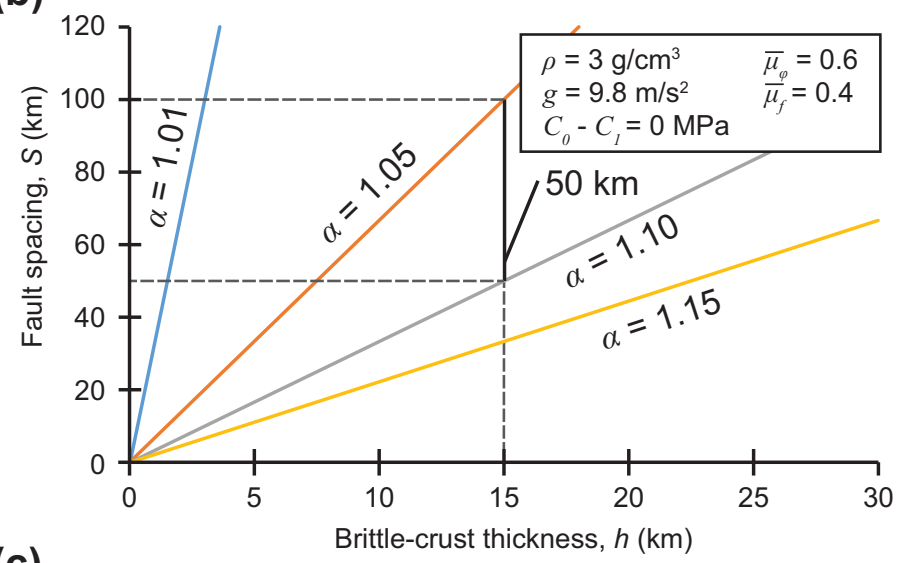

(c)

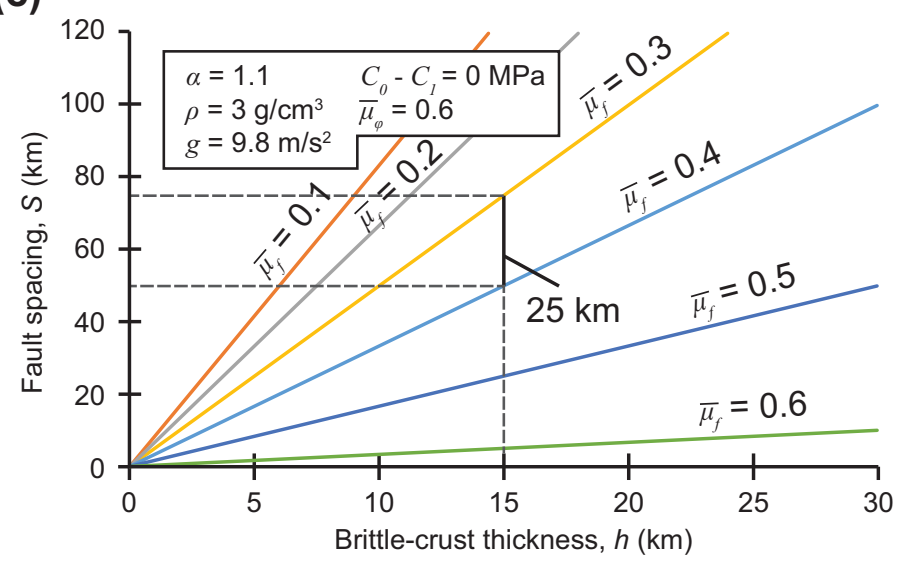

Zuza et al. - Figure 5 


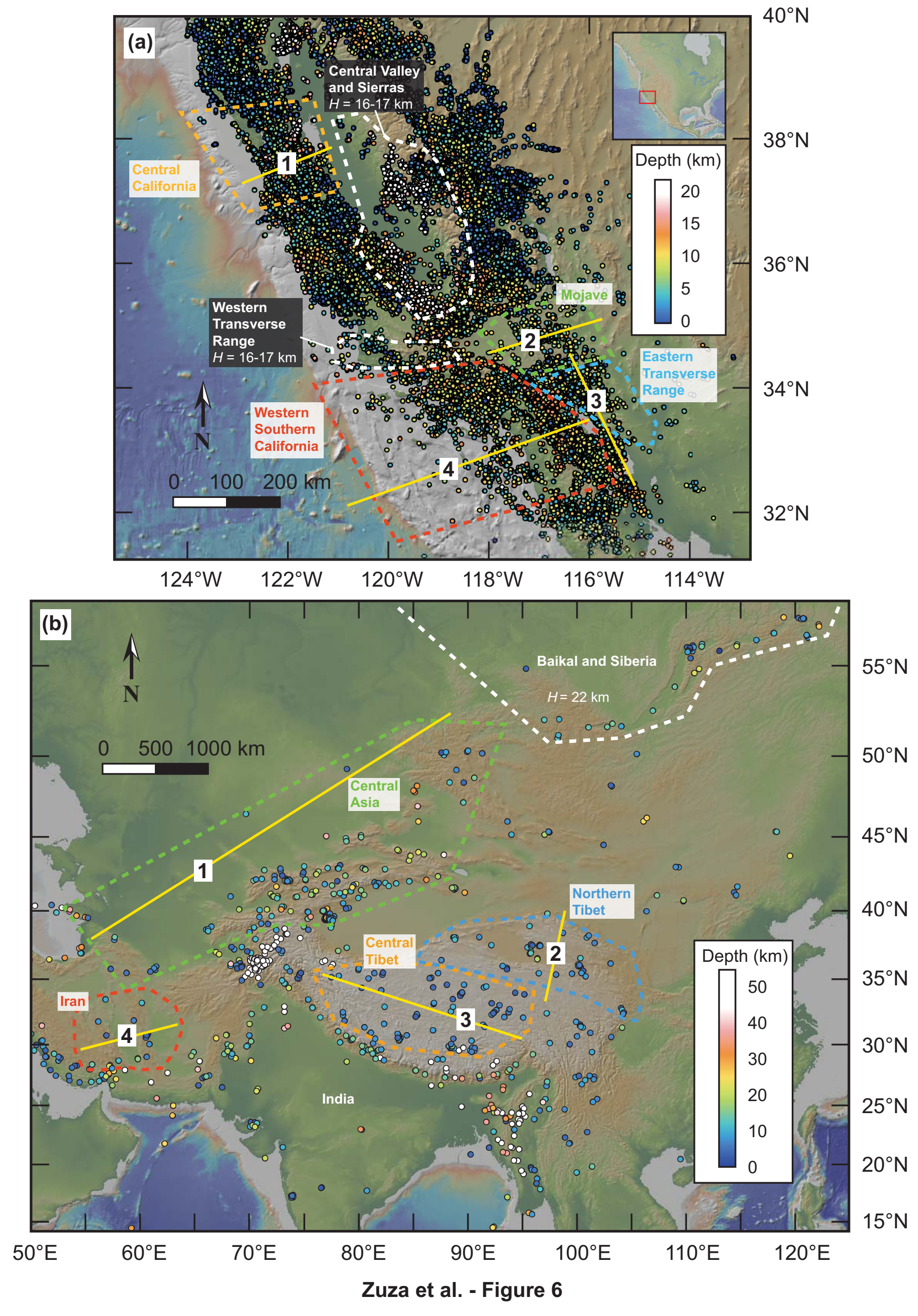



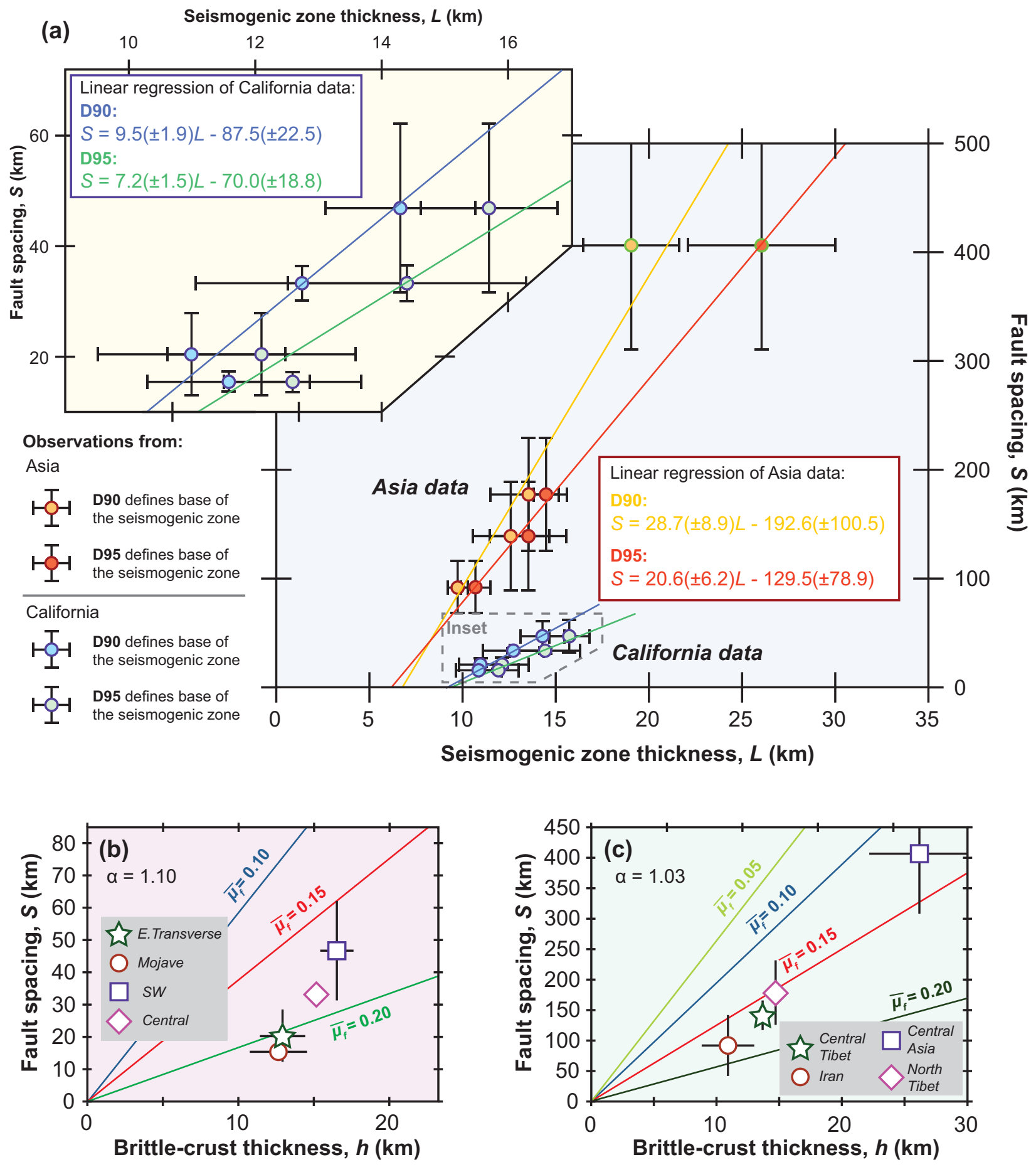

Zuza et al. - Figure 7 


\section{Continental strike-slip faulting} (fault-parallel shear)

(a)

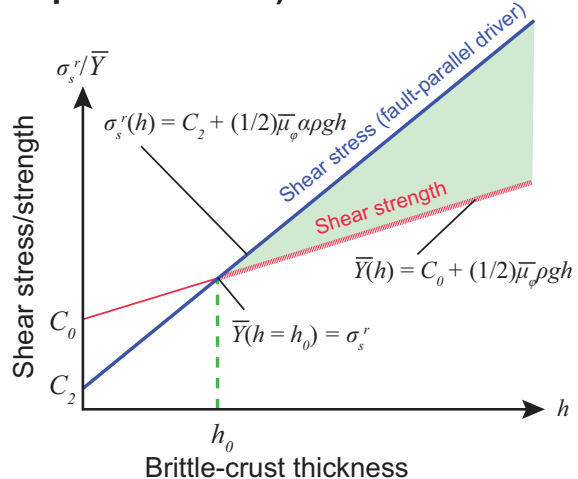

(b)

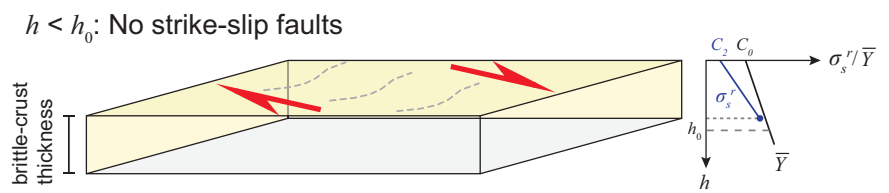

$h \geq h_{0}$ : Strike-slip faults generated

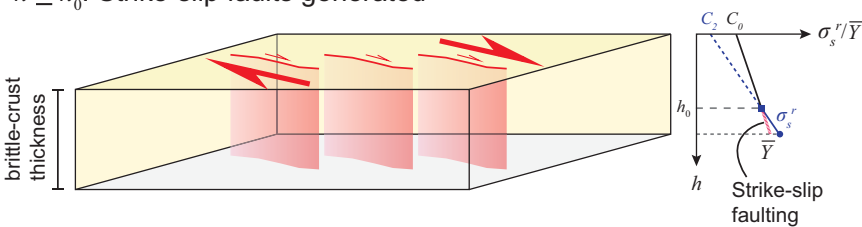

\section{Analogue experiment strike-slip faulting} (basal shear)

(c)

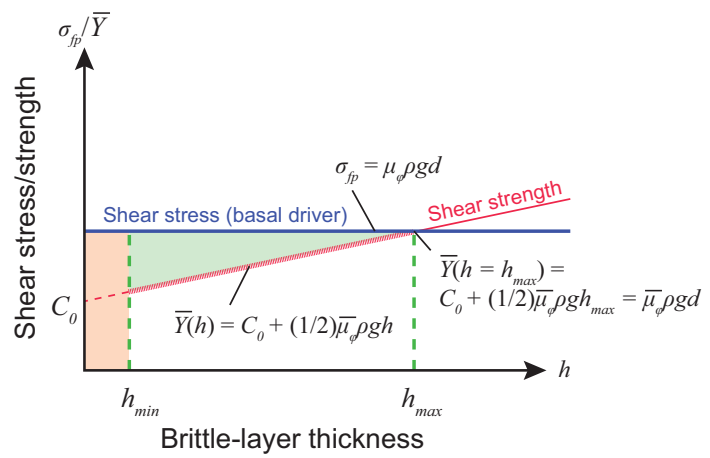

(d)

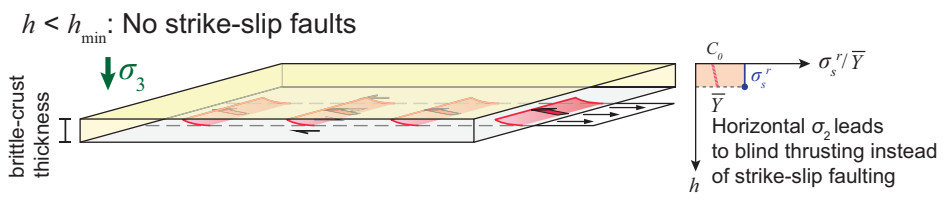

$h_{\min }<h<h_{\max }:$ Strike-slip faults generated
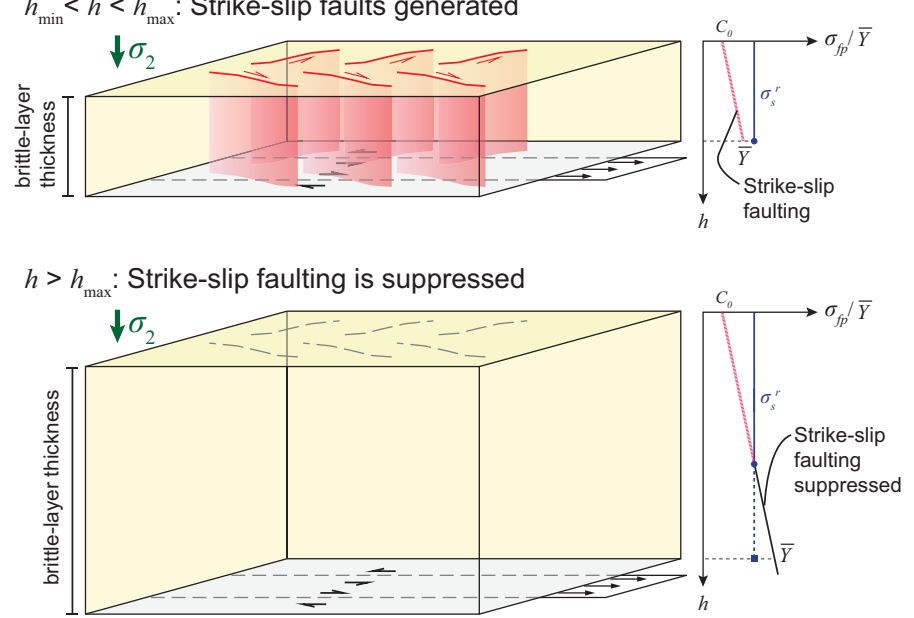

\section{Zuza et al. - Figure 8}

